Simulação numérica do escoamento em torno de um cilindro utilizando o Método das Fronteiras Imersas

\author{
Evelise Roman Corbalan Góis
}




\title{
Simulação numérica do escoamento em torno de um cilindro utilizando o Método das Fronteiras Imersas
}

\author{
Evelise Roman Corbalan Góis
}

Orientador: Prof. Dr. Leandro Franco de Souza)

Dissertação apresentada ao Instituto de Ciências Matemáticas e de Computação - ICMC-USP, como parte dos requisitos para obtenção do título de Mestre em Ciências - Ciências de Computação e Matemática Computacional.

\section{"VERSÃO REVISADA APÓS A DEFESA"}

Data da Defesa:

$14 / 09 / 2007$

Visto do Orientador:

USP - São Carlos

Novembro/2007 
Dedico este trabalho aos meus amados avós, Antônio e Maria Corbalan. 


\section{Agradecimentos}

A Deus, motivo principal da minha existência e da minha permanência em São Carlos. A Maria Santíssima, ao mesmo tempo doçura de colo materno e força de mulher lutadora.

Aos meus queridos pais, Bete e Elias, por todo amor, ensinamentos, correções e todo sacríficio para que eu tivesse sempre o melhor e ao meu irmão Eduardo. Obrigada por me ensinarem a ser o que eu sou hoje. Amo muito vocês!

À minha madrinha Sônia e ao Tio Her, pelas longas conversas, apoio e incentivo sempre! É impossível descrever o quanto vocês são importantes pra mim! Também amo muito vocês!

A tia Nenê, Tio Zé, Tio Toninho, Rodrigo, Jú e Zê, motivos da minha alegria, sem os quais minha vida não faz sentido. À tia Edna, pelo exemplo deixado e por cuidar de nós de lá do céu. Aos meus avós, Antônio e Maria, meus exemplos, minhas doçuras! Meu amor por vocês é infinito!

Ao Prof.Dr. José Roberto Nogueira e sua esposa Socorro, pelos ensinamentos, amizade e pelo exemplo profissional e moral durante minha iniciação científica e minha primeira experiência como professora. Os ensinamentos de vocês me serão eternos.

Aos amigos do Lcad: Alex, Cláudio, Gil, João Paulo, Kurokawa, Gardenal, Dantas, Carol e Aninha pela ajuda e carinho sempre. Ao Cacheffo, Hélio e Rodrigo, meus primeiros amigos em São Carlos.

À minha amiga irmã de toda a vida, Priscila.

Ao meu amor, André, por todos os momentos. Você me faz crescer e me faz querer ser melhor a cada dia! Te amo!

Ao Ministério Universidades Renovadas, e em especial aos luquinhas de São Carlos: Mário, Carlão, Lucas, Cá, João, Aderson, Sara, Carol, Justo, Rafa, Dan, Tina, Fer, Pam, Bel, Helton, Cé, Henrique, Van, Claudinei, Jú, BB, Fi, Lú, Wilsinho, Chris, Maikon, Fred, Heltinho, Gustavo, Karen, Cidinha, e todos os outros que passaram pela minha vida nestes dois anos... Agradeço pelo companheirismo, pelas orações em todos os momentos, por serem minha família aqui em São Carlos, uma família que nasceu pela fé! Amo cada um de vocês!

Aos Professores do Lcad, e de uma maneira muito especial ao meu orientador, Prof. Dr. Leandro Franco de Souza, pelos seus ensinamentos, profissionalismo e incentivo sempre. Obrigada por ter acreditado em mim e no meu trabalho em todos os momentos, inclusive nos de dificuldade, me fazendo crescer como pesquisadora e como pessoa. Levarei seu exemplo pra sempre comigo! 
Nada te perturbe Nada te espante Tudo passa,

Só Deus não muda. A paciência Tudo alcança Quem tem a Deus, Nada lhe falta.

Só Deus basta.

Santa Teresa D'Ávila 


\section{Sumário}

Lista de Figuras $\quad$ ix

Lista de Tabelas $\quad$ xi

Resumo xiii

$\begin{array}{ll}\text { Abstract } & \text { XV }\end{array}$

1 Introdução $\quad \mathbf{1}$

1.1 O estudo dos movimentos dos fluidos e as Equações de Navier-Stokes . . . 2

1.1.1 Algumas definições importantes . . . . . . . . . . . . . . . . . 3

1.1.2 Formulação Vorticidade-Velocidade . . . . . . . . . . . . . . . . . 4

1.2 Estrutura do trabalho . . . . . . . . . . . . . . . . . 5 5

2 O fenômeno da Atrelagem Síncrona $\quad 7$

2.1 Estudos numéricos e experimentais . . . . . . . . . . . . . . . . 7

2.2 Considerações Finais . . . . . . . . . . . . . . . . . . . 17

3 Métodos $\quad 19$

3.1 Aproximação das Derivadas Espaciais por Diferenças Finitas . . . . . . . . 19

3.1.1 Cálculo da Primeira Derivada . . . . . . . . . . . . . . . . 20

3.1 .2 Cálculo da Segunda Derivada . . . . . . . . . . . . . . . . . 21

3.2 Derivadas Temporais e o Método de Runge-Kutta . . . . . . . . . . . . . . 22

3.3 Resolução da Equação de Poisson e Método Multigrid . . . . . . . . . . . . . 23

3.4 O Método das Fronteiras Imersas . . . . . . . . . . . . . . . 26

3.4.1 Método das Fronteiras Imersas: Vantagens e Desvantagens . . . . . 27

3.4 .2 Formulação . . . . . . . . . . . . . . . . . . . . . . . . . 29

3.5 Cálculo dos Coeficientes de Arrasto e Sustentação utilizando a Técnica de

Volume de Controle . . . . . . . . . . . . . . . . . . 32

3.6 Considerações Finais . . . . . . . . . . . . . . . . . . . . . . . . . . 33

4 Resultados $\quad 35$

4.1 Escoamento em torno do cilindro estacionário . . . . . . . . . . . . . 36

4.2 Escoamento em torno do cilindro oscilante . . . . . . . . . . . . . . 37

4.2.1 Oscilação na mesma direção do escoamento . . . . . . . . . . . . . . . . 38

4.2 .2 Oscilação na direção perpendicular ao escoamento . . . . . . . . . . . 43 
4.2 .3 Oscilação Angular . . . . . . . . . . . . . . . . . . . . . . . . . . 47

4.3 Considerações finais . . . . . . . . . . . . . . . . . . . . 52

5 Conclusões $\quad 55$

5.1 Trabalhos Futuros . . . . . . . . . . . . . . . . . 56

$\begin{array}{ll}\text { Referências Bibliográficas } & 58\end{array}$ 


\section{Lista de Figuras}

3.1 Superfície de controle adotada. . . . . . . . . . . . . . . . . . . . . . 32

4.1 Coeficientes de arrasto e sustentação para $R e=100$ quando o cilindro está em repouso. . . . . . . . . . . . . . . . . . . . 36

4.2 Contorno de vorticidade para $R e=100$ quando o cilindro está em repouso. 37

4.3 Coeficientes de arrasto e sustentação para $R e=200$. Cilindro estacionário 38

4.4 Linhas de vorticidade para o cilindro estacionário $-R e=200$. . . . . . 38

4.5 Comparação entre os coeficientes de sustentação para o cilindro oscilando na direção $x \operatorname{com} A=0,1, F=0,55$ e $R e=200$. Gráfico à esquerda: presente trabalho. Gráfico à direita: resultados de Al-Mdallal, Lawrence e Kocabiyik(M.AL-MDALLAL; LAWRENCE; KOCABIYIK, 2007) . . . . . . . . . 39

4.6 Comparação dos coeficientes de sustentação para o cilindro oscilando na direção $x \operatorname{com} A=0,1, F=2,2$ e $R e=200$. Gráfico à esquerda: presente trabalho. Gráfico à direita: resultados de Al-Mdallal, Lawrence e Kocabiyik(M.AL-MDALLAL; LAWRENCE; KOCABIYIK, 2007) . . . . . . . . .

4.7 Comparação entre os coeficientes de sustentação para o cilindro oscilando na direção $x \operatorname{com} A=0,1, F=2,8$ e $R e=200$. Gráfico à esquerda: presente trabalho. Gráfico à direita: resultados de Al-Mdallal, Lawrence e Kocabiyik(M.AL-MDALLAL; LAWRENCE; KOCABIYIK, 2007) . . . . . . . . . 40

4.8 Esteira de vórtices pra o cilindro oscilante e estacionário respectivamente. . 41

4.9 Contornos de vorticidade para $\mathrm{Re}=300, \mathrm{~F}=1,4$ e $\mathrm{A}=0,05$. Esquerda: presente trabalho. Direita: Nobari e Naderan (NOBARI; NADERAN, 2006) . 41

4.10 Linhas de vorticidade para o cilindro oscilando na direção $x$ com frequência $F=0,5$ e $R e=190 \ldots \ldots \ldots$. . . . . . . . . . . . . . 42

4.11 Linhas de vorticidade para o cilindro oscilando na direção $x$ com frequência $F=1,5$ e $R e=190$. . . . . . . . . . . . . . . . . 43

4.12 Linhas de vorticidade para o cilindro oscilando na direção $x$ com frequência $F=2,0$ e $R e=190 \ldots \ldots \ldots \ldots \ldots$

4.13 Linhas de vorticidade para o cilindro oscilando na direção $x$ com frequência $F=3,0$ e $R e=190$.

$4.14 C_{d}$ e $C_{l}$ para o cilindro oscilando na direção $y \operatorname{com} A=0,2, F=0,6$,

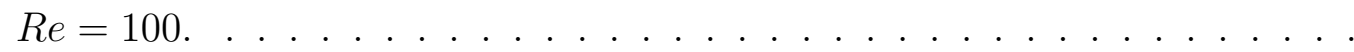

4.15 Linhas de vorticidade para o cilindro oscilando na direção $y$ com $A=0,2$, $F=0,6$ e $R e=100$. 
$4.16 C_{d}$ e $C_{l}$ para o cilindro oscilando na direção $y$ com $A=0,2, F=1,05$,

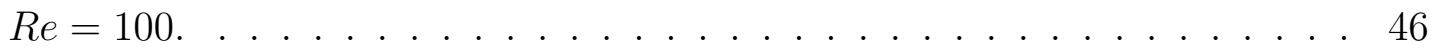

4.17 Linhas de vorticidade para o cilindro oscilando na direção $y \operatorname{com} A=0,2$, $F=1,05$ e $R e=100 \ldots \ldots \ldots \ldots \ldots$. . . . . . . . . . . 46

$4.18 C_{d}$ e $C_{l}$ para o cilindro oscilando na direção $y \operatorname{com} A=0,4, F=0,6$, $R e=100 \ldots \ldots \ldots \ldots \ldots \ldots$. . . . . . . . . . . . . . . . . . .

4.19 Linhas de vorticidade para o cilindro oscilando na direção $y$ com $A=0,4$, $F=0,6$ e $R e=100$. . . . . . . . . . . . . . . . . 47

$4.20 C_{d}$ e $C_{l}$ para o cilindro oscilando na direção y com $A=0,4, F=1,05$, $R e=100 \ldots \ldots \ldots \ldots \ldots \ldots \ldots$

4.21 Linhas de vorticidade para o cilindro oscilando na direção $y$ com $A=0,4$,

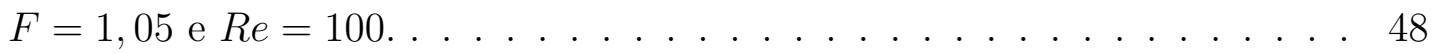

4.22 Coeficiente de sustentação para o cilindro rotativo com ângulo máximo de rotação de $15^{\circ}$ e frequência de oscilação $F=0.15$. . . . . . . . . . . . . . 49

4.23 Coeficiente de sustentação para o cilindro rotativo com ângulo de $15^{\circ}$ e frequência de oscilação $F=0.17$. . . . . . . . . . . . . . . . . 50

4.24 Coeficiente de sustentação para o cilindro rotativo com ângulo de $30^{\circ}$ e frequência de oscilação $F=0.14$. . . . . . . . . . . . . . . . 51

4.25 Coeficiente de sustentação para o cilindro rotativo com ângulo de $30^{\circ} \mathrm{e}$ frequência de oscilação $F=0.17$. . . . . . . . . . . . . . . . 51

4.26 Coeficiente de sustentação para o cilindro rotativo com ângulo de $30^{\circ} \mathrm{e}$ frequência de oscilação $F=0.20$. . . . . . . . . . . . . . . . 52

4.27 Coeficiente de sustentação para o cilindro rotativo com ângulo de $60^{\circ}$ e frequência de oscilação $F=0.14$. . . . . . . . . . . . . . . 53

4.28 Coeficiente de sustentação para o cilindro rotativo com ângulo de $60^{\circ}$ e frequência de oscilação $F=0.17 \ldots \ldots \ldots$. . . . . . . . . . 53

4.29 Coeficiente de sustentação para o cilindro rotativo com ângulo de $60^{\circ} \mathrm{e}$ frequência de oscilação $F=0.20$. . . . . . . . . . . . . . . 54 


\section{Lista de Tabelas}

4.1 Comparação do $C_{d}$ e $C_{l}$ máximo para $R e=100$ e para o cilindro em repouso. 37

4.2 Comparação $C_{l}$ para o caso em que o cilindro oscila com $A=0,2$. . . . . 49

4.3 Comparação do $C_{l}$ máximo para para o cilindro rotacionando com ângulo máximo de $15^{\circ}$. . . . . . . . . . . . . . . . . . . . . 50

4.4 Comparação do $C_{l}$ máximo para cilindro rotacionando com ângulo máximo

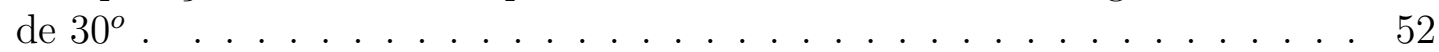

4.5 Comparação do $C_{l}$ máximo para cilindro rotacionando com ângulo máximo

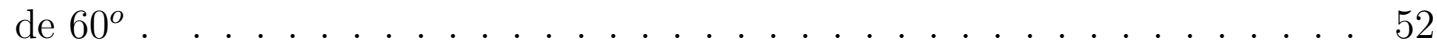




\section{Resumo}

O escoamento em torno de corpos tem sido objeto de estudo de muitos pesquisadores e é muito explorado experimental e computacionalmente, devido a sua grande aplicabilidade na engenharia. No entanto, simular computacionalmente este tipo de escoamento requer uma atenção especial ao escolher o tipo malha a ser utilizado. Em muitos casos fazse necessário o uso de uma malha que se adapte ao contorno do obstáculo, o que pode ocasionar um aumento no esforço computacional. Um maneira de contornar este problema é a utilização do Método das Fronteiras Imersas, que possibilita o uso de malha cartesiana na simulação computacional do escoamento em torno de obstáculos. Isso é possível através da adição de um termo forçante nas equações que modelam o escoamento, e assim as forças que agem sobre o contorno do corpo são transferidas diretamente para a malha. O objetivo deste trabalho de mestrado foi implementar o método das Fronteiras Imersas e simular o escoamento em torno de um cilindro circular em repouso, movimentando-se na mesma direção do escoamento, na direção perpendicular ao escoamento, ou rotacionando em torno do próprio eixo. As simulações computacionais possibilitaram a captura do fenômeno de Atrelagem Síncrona, caracterizado pela sincronia entre a frequência de desprendimento natural de vórtices e a frequência de oscilação do mesmo. O Método das Fronteiras Imersas mostrou um ótimo desempenho quando comparado a resultados experimentais e numéricos encontrados na literatura.

Palavras-chave: escoamento em torno de cilindros, fenômeno da atrelagem síncrona, simulações com baixo Reynolds, Método das Fronteiras Imersas. 


\section{Abstract}

The flow around bodies have been studied by many researchers. Both experimental and computational approaches have been extensively explored in researches on flow around bodies and have been applied in many engeneering problems. However, to choose an appropriate type of mesh to perform computational simulations of this type of problem requires special attention. In many cases, it is necessary to use a mesh that is able to conform to the boundary if a given obstacle. The need to perform this adaptation may increase the computational effort. The Immersed Boundary Method enables the use of cartesian meshes to perform computational simulations of flows around obstacles. The idea of this method is to add a forcing term in the equations that model the flow. Thus, the forces applied on the body boundaries are directly transfered to the mesh. The aim of this work was to perform a computational implementation of the Immersed Boundary Method to simulate the flow over a oscilating circular cylinder. This oscilation may be inline with the flow, cross-flow, or rotating. The computational simulations enabled the capture of the lock-in phenomena, which consists of the syncronization between the vortex shedding frequency and the cylinder oscilation frequency. The results obtained from the computational simulations using the Immersed Boundary Method were in good agreement with the numerical and experimental results found in the literature.

Keywords: flow over a cylinder, lock-in phenomena, simulations with low Reynolds Number, Immersed Boundary Method 


\section{Introdução}

Estudar o escoamento em torno dos corpos sempre foi desafiador para pesquisadores em Dinâmica dos Fluidos Computacional, principalmente quando o escoamento sofre influências externas. Este estudo torna-se fundamental para o entendimento de muitas situações do cotidiano, como o escoamento em torno de tubos de perfuração em plataformas de extração de petróleo, ao redor de perfis de asas de aeronaves e automóveis.

Um particular interesse na área de escoamentos em torno de obstáculos é a investigação do fenômeno de atrelagem síncrona. Esse fenômeno foi descoberto há mais de trezentos anos por Christian Huygens que observou que dois pêndulos colocados lado a lado têm uma tendência a sincronização. Muitos estudos já foram realizados nesse campo, como o estudo sobre o cilindro de seção circular e quadrada, com o cilindro em repouso e em movimento, na direção paralela ao escoamento, na direção normal ao mesmo ou ainda rotacionando em torno do próprio eixo. O entendimento do fenômeno da atrelagem síncrona é de grande importância pois permite entender a física de escoamentos ao redor de tubulações e cabos de força, por exemplo.

Neste trabalho, as simulações do escoamento de um fluido em torno de um cilindro circular serão feitas através da utilização do Método das Fronteiras Imersas. Os objetivos são verificar e validar o modelo numérico proposto para o estudo de escoamentos ao redor de corpos rígidos. Os resultados são verificados e validados quando comparados aos resultados numéricos e experimentais encontrados na literatura, respectivamente. $\mathrm{O}$ cilindro que serve como obstáculo ao escoamento pode encontrar-se em repouso, movendose na mesma direção ou na direção perpendicular ao escoamento, ou ainda efetuando uma oscilação angular em torno do próprio eixo.

O método das Fronteiras Imersas foi proposto em 1972 por Charles S. Peskin com o objetivo de simular o escoamento de sangue em um coração humano. Esse método tem 
características próprias, diferentes das comumente encontradas na dinâmica dos fluidos computacional: ao invés de utilizar malhas numéricas que se adaptam ao formato do sólido que serve como obstáculo ao escoamento, ele discretiza as equações que modelam o escoamento em uma malha cartesiana, adicionando um termo forçante nas equações governantes. Este termo forçante é responsável por indicar ao escoamento a localização do obstáculo no mesmo. Essa classe alternativa na dinâmica dos fluidos computacional vem sendo introduzida no mundo da aerodinâmica computacional, principalmente na simulação de escoamentos sobre superfícies com geometrias complexas e fronteiras móveis. As fronteiras móveis, particularmente, na interação fluido-estrutura, é um tópico que tem chamado a atenção dos pesquisadores. A aeroelasticidade aérea é um exemplo deste tipo de interação estudado pelas engenharias mecânica e aeronáutica. Isto resulta na necessidade do estudo de ferramentas computacionais adequadas, que possam simular o fenômeno. O método das Fronteiras Imersas tem sido, dessa forma, muito utilizado para simular o escoamento em torno de geometrias complexas, como colônias de corais, ao redor de veículos, componentes eletrônicos, e objetos em queda livre, além de ser utilizado no estudo da aerodinâmica da navegação e do nado de peixes. Alguns trabalhos na literatura, como o de Lai e Peskin (LAI; PESKIN, 2000) fazem uma distinção deste método em dois tipos: o Método das Fronteiras Imersas, que se aplica a obstáculos com fronteira móvel, e o Método da Fronteira Virtual, que se aplica quando o obstáculo tem fronteiras rígidas. No decorrer desta dissertação, o método das Fronteira Imersas fará referência ao escoamento em torno do obstáculo rígido.

\subsection{O estudo dos movimentos dos fluidos e as Equações de Navier-Stokes}

O movimento dos fluidos é um fenônemo que chama a atenção da humanidade desde os tempos mais remotos. Os egípcios construíram relógios de água e os romanos construíram aquedutos para transportar água para suas cidades. Assim, historicamente o comportamento dos fluidos foi estudado primeiramente de forma experimental, muito antes de ser traduzido para a linguagem matemática. Isso explica o surgimento da hidráulica, que trata dos movimentos de líquidos em tubos, canais e outros dispositivos, antes da hidrodinâmica, que estabelece relações entre o movimento do fluido e suas forças causadoras. Leonard Euler é considerado um dos fundadores da hidrodinâmica, pois foi quem primeiro deduziu as equações de movimento de fluidos, as chamadas equações de Euler. Mas foram os trabalhos dos franceses Claude Navier (1822), Simeon Poisson (1829) e do inglês George Stokes (1845) que impulsionaram as descrições matemáticas do movimento dos fluidos. Foi a partir desses trabalhos que foram formuladas as equações de Navier-Stokes.

As equações de Navier-Stokes modelam escoamentos de fluidos compressíveis e incom- 
pressíveis, turbulentos e laminares, e representam a formulação matemática do princípio da conservação da quantidade de momento linear, dado pela Segunda Lei de Newton.

Assim, em coordenadas bidimensionais, para escoamentos incompressíveis e isotérmicos, as equações que modelam este escoamento são dadas por:

$$
\begin{gathered}
\frac{\partial u}{\partial x}+\frac{\partial v}{\partial y}=0 \\
\frac{\partial u}{\partial t}+\frac{\partial u^{2}}{\partial x}+\frac{\partial u v}{\partial y}=-\frac{1}{\rho} \frac{\partial p}{\partial x}+\nu\left(\frac{\partial^{2} u}{\partial x^{2}}+\frac{\partial^{2} u}{\partial y^{2}}\right) \\
\frac{\partial v}{\partial t}+\frac{\partial v^{2}}{\partial y}+\frac{\partial u v}{\partial x}=-\frac{1}{\rho} \frac{\partial p}{\partial y}+\nu\left(\frac{\partial^{2} v}{\partial x^{2}}+\frac{\partial^{2} v}{\partial y^{2}}\right)
\end{gathered}
$$

onde $u$ é a componente da velocidade na direção $x, v$ é a componente da velocidade na direção $y, \rho$ é a densidade, $p$ é a pressão, e $\nu$ é sua viscosidade cinemática.

\subsubsection{Algumas definições importantes}

Nesta subseção, serão consideradas algumas definições básicas do estudo do escoamento dos fluidos, cujos termos serão citados várias vezes no decorrer desta dissertação.

O número de Reynolds expressa a razão entre as forças inerciais e as forças viscosas em um escoamento, e pode ser escrito como

$$
R e=\frac{\text { forças inerciais }}{\text { forças viscosas }}=\frac{\rho L U}{\mu}
$$

onde $\rho$ é a densidade e $\mu$ a viscosidade do fluido. $L$ e $V$ são comprimentos e velocidade característicos do escoamento. De acordo com o número de Reynolds, pode-se perceber a influência das forças inerciais e das forças viscosas no escoamento. Quando $R e \gg 1$, as forças viscosas passam a ser importantes somente em regiões próximas a superfícies sólidas.

A frequência com que o cilindro que serve como obstáculo ao escoamento oscila é definida como

$$
F=\frac{f_{e}}{f_{0}}
$$

onde $f_{e}$ é a frequência de oscilação do cilindro em movimentação induzida e $f_{0}$ é a frequência de desprendimento natural de vórtices à jusante do cilindro, que depende de $R e$ e $S t$ em determinadas faixas e geometrias.

O número de Strouhal St é um número adimensional, definido como 


$$
S t=\frac{f_{0} L}{U}
$$

onde $f$ é a frequência de desprendimento de vórtices da esteira de vón Kármán, $L$ é o tamanho característico do vórtice e $U$ é a velocidade do escoamento. O número de Strouhal normalmente depende do número de Reynolds.

\subsubsection{Formulação Vorticidade-Velocidade}

Escrever as equações de Navier-Stokes na formulação alternativa de vorticidade-velocidade tem a grande vantagem de eliminar o cálculo da pressão nas equações de momento, fazendo com que a equação da continuidade seja satisfeita diretamente pelo campo de velocidades.

Se forem consideradas as equações de momento de Navier-Stokes na forma nãoconservativa dadas por 1.2 e por 1.3 , e calculando

$$
\frac{\partial(1.2)}{\partial x}+\frac{\partial(1.3)}{\partial y}
$$

e obtém-se:

$$
\begin{aligned}
& \frac{\partial}{\partial t}\left(\frac{\partial u}{\partial y}-\frac{\partial v}{\partial x}\right)+u \frac{\partial}{\partial x}\left(\frac{\partial u}{\partial y}-\frac{\partial v}{\partial x}\right)+v \frac{\partial}{\partial y}\left(\frac{\partial u}{\partial y}-\frac{\partial v}{\partial x}\right)= \\
& \nu\left[\frac{\partial^{2}}{\partial x^{2}}\left(\frac{\partial u}{\partial y}-\frac{\partial v}{\partial x}\right)+\frac{\partial^{2}}{\partial y^{2}}\left(\frac{\partial u}{\partial y}-\frac{\partial v}{\partial x}\right)\right]
\end{aligned}
$$

onde o termo

$$
\frac{\partial u}{\partial y}-\frac{\partial v}{\partial x}
$$

é chamado de vorticidade $\omega$, e representa a medida da rotação de um elemento de fluido em torno de um ponto. Assim, uma equação em função da vorticidade pode ser escrita, que fica da forma:

$$
\frac{\partial \omega}{\partial t}+u \frac{\partial \omega}{\partial x}+v \frac{\partial \omega}{\partial y}=\nu\left(\frac{\partial^{2} \omega}{\partial x^{2}}+\frac{\partial^{2} \omega}{\partial y^{2}}\right)
$$

A formulação da vorticidade-velocidade baseia-se na solução numérica da equação do transporte da vorticidade dada por 1.10 juntamente com a equação da continuidade dada por 1.1. 


\subsection{Estrutura do trabalho}

A presente dissertação encontra-se organizada da seguinte maneira:

Capítulo 1 É efetuada a contextualização do trabalho, juntamente com algumas definições importantes e formulações que servem como pré-requisitos para o desenvolvimento do trabalho.

Capítulo 2 Consiste numa revisão de trabalhos sobre o escoamento em torno dos cilindros e do fenômeno da Atrelagem Síncrona, tanto no aspecto experimental quanto no aspecto numérico.

Capítulo 3 Descreve todos os métodos numéricos e as discretizações envolvidas no trabalho, e de maneira mais aprofundada, o Método das Fronteiras Imersas.

Capítulo 4 Apresenta a validação e a verificação do código implementado baseado no Método das Fronteiras Imersas e descreve os resultados numéricos encontrados para o caso em que o cilindro encontra-se em repouso, oscilando na mesma direção do escoamento, na direção transversal ao escoamento, ou ainda rotacionando em torno do próprio eixo.

Capítulo 5 Apresenta as conclusões e aspectos positivos deste trabalho, juntamente com propostas de aperfeiçoamento e possibilidades de pesquisas futuras. 


\section{Capítulo \\ 2 \\ O fenômeno da Atrelagem Síncrona}

O escoamento em torno de obstáculos e os fenônemos decorrentes de tal escoamento intrigam e chamam a atenção da comunidade científica já há algum tempo, assim como o estudo dos fatores que interferem em seus fenômenos físicos, como a formação e a frequência de desprendimento de vórtices. A movimentação desse obstáculo, por uma força externa é um desses fatores e pode causar um interessante fenômeno, chamado de Atrelagem Síncrona, conhecido como Lock-in Phenomena. Esse fenômeno caracteriza-se pela sincronia entre o movimento do cilindro e o desprendimento de vórtices a jusante dele.

Este capítulo dedica-se a uma revisão dos estudos teóricos e experimentais sobre o escoamento em torno de um cilindro e o fenômeno de atrelagem síncrona, organizada em ordem cronológica. Alguns destes trabalhos experimentais e numéricos foram utilizados na validação e verificação dos resultados obtidos através das simulações efetuadas utilizando o método das Fronteiras Imersas. Estes resultados serão discutidos no capítulo 4 desta dissertação.

\subsection{Estudos numéricos e experimentais}

Fenômenos naturais de escoamento em torno de obstáculos relacionados com o escoamento em torno de um cilindro vibrando foi a motivação de Berger e Willie (BERGER; WILLIE, 1972) para realizar estudos experimentais, com número de Reynolds entre 40 e 80 . O artigo faz um histórico das esteiras de vórtices sobre ilhas oceânicas, e relata que a primeira indicação de um escoamento com características periódicas foi registrada na estação meteorológica de Norwegian, nas ilhas árticas de Jan Mayan. Esse fato, ocorrido em 1939, foi explicado como sendo uma separação horizontal de vórtices periódicos. Em 1949, dez 
anos depois, foi encontrada uma esteira de von Kármán com eixo vertical de vorticidade. Com a utilização de fotos fornecidas por satélite na década de sessenta, os estudos das esteiras de von Kármán ganharam um novo interesse. Os primeiros artigos dessa década atribuíam a visibilidade das esteiras a instabilidades geotrópicas das correntes de vento, que foi introduzida por um componente vertical no escoamento na vizinhança de uma ilha que funcionou como obstáculo. No ano de 1965, Chopra e Hubert (CHOPRA; HUBERT, 1965) insinuaram relações de similaridade entre as esteiras de von Kármán produzidas pelo escoamento em torno cilindros infinitamente longos e a esteira de vórtices de nuvens na Ilha da Madeira. O ponto de partida para comparações entre os resultados experimentais e o fenômeno observado na Ilha da Madeira foi em 1954. A maneira utilizada para calcular efetivamente a viscosidade em vórtices atmosféricos foi assumir para um dado parâmetro valores idênticos aos obtidos experimentalmente, juntamente com dados observados nas fotografias das nuvens. Mesmo com esses dados, a velocidade dos vórtices obtidas por Chopra e Hubert (CHOPRA; HUBERT, 1965) foram insatisfatórias, justificadas por algum erro no cálculo da viscosidade ou no valor assumido para a circulação inicial.

Berger e Willie (BERGER; WILLIE, 1972) dedicaram um capítulo de seu trabalho ao estudo da formação da esteira de vórtices, onde apresentam resultados empíricos de experimentos em túnel de vento com fluidos homogêneos e outro capítulo ao estudo das vibrações do cilindro. Até a edição do trabalho de Berguer e Willie, pouco era conhecido sobre a interação entre um cilindro em oscilação e seu escoamento periódico. Esta oscilação pode ser induzida artificialmente ou ser consequência natural do escoamento em torno do obstáculo. Já era conhecido que o sistema formado por um escoamento em torno de um obstáculo comporta-se como um auto-oscilador não linear onde o escoamento é o oscilador e o cilindro é forçado a vibrar externamente. Até essa época, o plano de oscilação utilizado era geralmente paralelo ao sentido do escoamento e a sincronização ou Lock-in era característica de um sistema não-linear formado pelo corpo sólido elástico e o escoamento. Outras características citadas por Berger e Willie (BERGER; WILLIE, 1972) para um oscilador não-linear auto excitado são a histerese, frequência de multiplicação e a supressão da esteira de vórtices. O termo histerese descreve o fenômeno em que propriedades características de interação da esteira com o cilindro são diferentes com o aumento ou diminuição da frequência de oscilação do cilindro. A frequência de multiplicação, também chamada de frequência de divisão foi descrita por Bishop e Hassan (BISHOP; HASSAN, 1964), que concluíram que a frequência de espalhamento dos vórtices durante o estado de sincronização na esteira $f_{n}$ quando o cilindro é forçado a vibrar é dada por um múltiplo da frequência do cilindro $f_{\text {cil }}$, ou seja, $f_{n}=m \cdot f_{c i l}$, para $m=1,2,3$. A supressão do espalhamento de vórtice, até essa época, ainda não tinha resultados efetivos para altos números de Reynolds.

Para realizar um estudo experimental sobre a esteira de vórtices gerada por um cilindro circular vibrando na direção paralela à corrente livre, Griffin e Ramberg (GRIFFIN; 
RAMBERG, 1976) utilizaram um túnel de vento nos ensaios, com um número de Reynolds igual a 190. A visualização da esteira de vórtices foi possível injetando-se aerosol nesse túnel e a velocidade foi medida usando-se um anemômetro de fio quente. O objetivo era identificar os limites do regime no qual as oscilações do cilindro passassem a controlar o processo de emissão de vórtices, ou seja, identificar os limites de regime onde ocorressem a atrelagem síncrona. Através desse estudo Griffin e Ramberg chegaram à conclusão de que no momento em que o cilindro é forçado a oscilar paralelamente à corrente livre, a atrelagem síncrona ocorre para a faixa entre 120 e $250 \%$ do valor da frequência natural de emissão de vórtices $f_{0}$. O valor mínimo para que a atrelagem ocorra cai à medida que a frequência de excitação aumenta. Além disso, foram identificados dois padrões de esteiras de vórtices emitidas a jusante do cilindro. O primeiro regime é caracterizado pela emissão de dois vórtices de sinais opostos por ciclo de movimento do cilindro. A frequência de oscilação destes dois vórtices é aproximadamente o dobro da frequência de oscilação natural de emissão de vórtices. No segundo regime verificou-se que um único vórtice por ciclo de movimento de cilindro foi emitido. A frequência $F$, para vórtices de mesmo sinal era igual à metade da frequência de excitação, numa faixa de $1,76<F<2,20$. Também foi colocado que o segundo regime compartilha de características comuns com o sistema em que o cilindro oscila na direção transversal à corrente livre, como a dependência inversa entre o espaçamento longitudinal dos vórtices emitidos e a frequência de excitação, ou seja, o espaçamento diminui na medida em que a frequência de excitação aumenta. Quando o cilindro oscila com uma frequência igual ao dobro da frequência natural de emissão de vórtices, o espaçamento longitudinal entre os vórtices na esteira se torna igual ao espaçamento entre os vórtices da esteira de um cilindro estacionário posicionado em um escoamento permanente. É igual também ao espaçamento de vórtices emitidos por um cilindro oscilando transversalmente à direção principal do escoamento, com frequência $f_{e}=f_{0}$. O espaçamento transversal entre os vórtices para oscilação longitudinal mostrou uma dependência similar a aquela apresentada pelos cilindros oscilando na direção transversal. À medida que a frequência de excitação aumenta, o espaçamento transversal diminui, até o limite em que ele desaparece completamente e a configuração topológica da esteira altera-se, passando para uma emissão incomum, onde três vórtices são emitidos a cada dois ciclos sucessivos de oscilação do cilindro.

Barbi, Favier e Maresca (BARBI; FAVIER; MARESCA, 1986) realizaram um estudo experimental sobre um escoamento estável e oscilatório sobre um cilindro circular, com velocidade média e número de Reynolds até 40.000. Até a época desse estudo, acreditavase que a esteira de vórtices proveniente do escoamento sobre um corpo rombudo em sua frequência natural (Número de Strouhal), ou quando sincronizada com uma instabilidade externa, dependia totalmente da direção da perturbação. Porém, os resultados obtidos por Barbi, Favier e Maresca (BARBI; FAVIER; MARESCA, 1986) indicaram que a frequência da esteira de vórtices pode variar de maneira mais suave quando direção da perturbação 
é alterada em valores próximos à ocorrência da atrelagem síncrona. A questão proposta pelo trabalho deles foi verificar se a atrelagem síncrona ocorre no caso de um cilindro fixo sujeito a um escoamento transiente com velocidade média diferente de zero. Para isso, foram realizados vários experimentos em túnel de vento em túnel de água e estudados dois casos: um com escoamento permanente e outro com escoamento oscilatório. No caso do escoamento permanente, com Reynolds de 45.000 até 105.000 no ar e de 3.200 até 110.000 na água. A ocorrência do fenômeno de atrelagem síncrona foi verificada, e os resultados obtidos no ar e na água foram similares. As medidas confirmaram a atração progressiva da frequência de desprendimento $F$ antes da atrelagem síncrona. As características gerais da atrelagem síncrona observadas para as oscilações paralelas à direção do escoamento foram confirmadas no escoamento com perturbações. Sendo $f_{0}$ a frequência inicial de desprendimento de vórtices e $f_{s}$ a frequência antes da atrelagem síncrona, pôde-se concluir que $f_{s}$ é igual a metade de $f_{0}$. A atrelagem síncrona é encontrada quando $f=2 f_{0}$, e algumas evidências mostraram que o fenômeno pode também ocorrer quando $f=4 f_{0}$. Foram encontrados dois diferentes modelos de vórtices: uma esteira com desprendimento simétrico, quando $\frac{f_{0}}{f_{s}}=1$, e um desprendimento alternado durante o fenômeno de atrelagem.

Armstrong, Barnes e Grant (ARMSTRONG; BARNES; GRANT, 1986) apresentaram medidas da frequência de desprendimento de vórtices em torno de um cilindro que sofre uma perturbação no caso bidimensional. A esteira de vórtices formada deu origem a uma oscilação de pressão agindo na superfície do corpo de forma que, se a oscilação aumenta, faz com que forças de arrasto ajam sobre o corpo. Já era sabido que a perturbação da força tem uma frequência igual a frequência de desprendimento de vórtices, ao passo que a perturbação da frequência de perturbação é o dobro da frequência de desprendimento de vórtices. Armstrong, Barnes e Grant se concentraram no estudo do escoamento em que o cilindro está em repouso e a velocidade do escoamento livre é oscilatória. Foi constatado que estes dois casos são equivalentes quando a amplitude da onda é grande se comparada ao diâmetro do cilindro. Foram utilizados três tipos obstáculos: um cilindro circular, um cilindro com seção de área $D$ e uma placa plana. O fenômeno de Atrelagem Síncrona foi estudado em cada caso. O critério utilizado para definir a atrelagem síncrona foi a proporção da frequência de desprendimento de vórtice em relação à frequência de perturbação tal que $0.495<F<0.505$. Assim, concluiu-se que a frequência de vórtices permanece igual a metade da perturbação da velocidade reduzida. Quando a amplitude da perturbação foi aumentada, a variação da atrelagem síncrona também se alterou.

Griffin (GRIFFIN, 1988) dedicou-se ao estudo das similaridades e relações entre vórtices num escoamento permanente bidimensional ao redor de corpos rombudos em oscilação, com diferentes ângulos de incidência de fluidos. Estudos para o caso em que o cilindro permanece sob perturbação ainda não haviam sido propostos. As relações de parentesco entre esses vórtices são caracterizadas pelo número de Strouhal. A questão de similaridade entre esteiras a jusante do sólido foi investigada por Griffin para o caso de desprendimento 
de vórtices no escoamento em torno de um cilindro circular, um corpo chato e um cilindro com seção de área $\mathrm{D}$, com uma perturbação induzida. Griffin percebeu que a pressão de base no cilindro no escoamento perturbado é visivelmente menor do que num escoamento estacionário. Perceberam também um aumento no coeficiente de arrasto quando a amplitude da oscilação atinge um dado valor. Novamente para um cilindro circular, os resultados obtidos por Griffin sugerem que a modificação e o controle da instabilidade básica ou nos mecanismos deformação da esteira podem garantir meios para efetuar mudanças substanciais no modelo de vórtices desprendidos a jusante do cilindro.

O trabalho de Oertl (OERTL, 1990) baseia-se no estudo de regiões absolutamente instáveis e na reformulação da teoria clássica de estabilidade da esteira de von Kármán. Para isso, foi considerado que a camada de separação da esteira é caracterizada pela mudança de uma instabilidade localmente absoluta para uma instabilidade absolutamente convectiva em um ponto específico do escoamento. Com o tempo, essa transição resulta num aumento da vorticidade, onde esses vórtices possuem sinais opostos. A perturbação, antes local, com o avanço no tempo passa a influenciar toda a área do escoamento. $\mathrm{O}$ estudo de instabilidade absoluta causava atritos entre a comunidade científica, principalmente entre os experimentalistas, o que ocorria por falta de provas experimentais sobre a existência de uma região absolutamente instável na esteira. O trabalho de Oertl tem o objetivo de demonstrar numericamente existência de uma região de instabilidade absoluta. Essa região é definida pela solução da equação de estado de Navier-Stokes. A grande contribuição é a possibilidade da determinação quantitativa da instabilidade, o que fornece ferramentas para suprimir o desenvolvimento da esteira de vórtices de von Kármán, como a utilização de manipulações geométricas que evitam a instabilidade absoluta na esteira. A discussão dos resultados numéricos serve como importante prova da existência de regiões de instabilidade absoluta. Oertl aproxima as equações de Navier-Stokes através de um método de Galerkin por elementos finitos modificado para possibilitar o avanço no tempo, aplicando-se um método explícito. Devido à instabilidade natural do escoamento na vizinhança do corpo, Oertl percebeu que a aplicação direta das condições de não deslizamento era fundamental para eliminar, por exemplo, alguma aproximação causada por extrapolação de pressão. Diferenças centradas foram aplicadas para eliminar falsos amortecimentos. Esse método foi capaz de capturar a instabilidade natural do escoamento, ou seja, o desprendimento de vórtices se desenvolve simetricamente sem a necessidade de uma força externa. Assim, Oertel distinguiu quatro diferentes regiões de instabilidade: uma região em estado de semi-estabilidade, uma região de crescimento linear, uma região de transição para o estado saturado, e uma região de saturação não-linear.

Através de experimentos do escoamento de um fluido em torno de um cilindro, o trabalho de Gu, Chyu e Rockwell (GU; CHYU; ROCKWELL, 1994) teve por objetivo garantir uma interpretação livre de ambiguidades para o desprendimento de vórtices a jusante do corpo, além de realizar um estudo da influência da frequência de movimentação do 
obstáculo neste desprendimento. O enfoque deste estudo foi a alteração da topologia das linhas de vorticidade. Para os experimentos, foram utilizados dois valores para o número de Reynolds: 185 e 5000. Esses valores foram escolhidos para melhor avaliar o tamanho dos vórtices desprendidos, pois, para $R e=185$ o coeficiente de pressão da base é muito alto, e o tamanho do vórtice formado é curto, em oposição ao que acontece para $R e=5000$. Os experimentos foram realizados em um túnel de água. A amplitude de oscilação do cilindro $A=0,2$, escolhida dessa forma por ser o ponto inicial em que o estado de sincronia pode ser mantido, mesmo para altos números de Reynolds. Todavia, esse valor não é grande o suficiente para manter a esteira de vórtices de von Kármán em larga escala a jusante do cilindro. Todos os experimentos foram registrados através das técnicas de referência de fase, onde fotografias são tiradas no instante correspondente ao deslocamento positivo máximo do cilindro em relação à sua posição de equilíbrio. Para $R e=185$, a análise das linhas de vorticidade revela que, no caso em que o cilindro encontra-se em repouso, e para uma variação na frequência de excitação entre $0,8 \leq$ $F \leq 1,1$, a topologia das linhas é a mesma e os exemplos de linhas não sugerem a concentração de vorticidade a jusante do cilindro. No entanto, ocorre uma mudança radical quando a frequência é alterada para $F=1,12$, com intersecção das linhas de vorticidade. Esse comportamento persiste até a frequência de $F=1,20$. Assim, essas frequências de oscilação resultam na concentração de vorticidade a jusante do cilindro. Comparando as linhas de contorno de vorticidade com o campo de velocidades, ainda para $R e=185$, percebeu-se que para variação da frequência entre 1,0 e 1,10, existem vórtices de sinais positivos e negativos que são desprendidos simultaneamente. Para frequência de 1, 12, o centro das linhas de contorno é aproximadamente coincidente com a concentração de vorticidade. É também efetuada uma comparação entre as linhas de vorticidade das frequências $F=1,0$ e $F=1,12$, onde pode-se perceber que a concentração de vorticidade para a frequência de $F=1,12$ é aproximadamente simétrica à concentração de vorticidade para a frequência de $F=1,00$. Os experimentos também foram conduzidos para $R e=$ 5000, com análises e comparações entre frequências de $F=0,85, F=0,89$. Em alguns casos, este desprendimento assemelha-se ao que ocorre em simulações com baixos números de Reynolds, com as frequências de $F=1,00$ e $F=1,20$. Através deste trabalho, não se pode concluir o valor de frequência $F$ a partir do qual ocorre mudanças na formação inicial dos vórtices. Para baixas amplitudes de excitação o valor crítico de $F$ pode ser relacionado com o coeficiente de pressão de base e desse modo, a formação de vórtices com o número de Reynolds.

Lu e Dalton (LU; DALTON, 1996) efetuaram uma simulação numérica bidimensional do escoamento uniforme de um fluido em torno de um cilindro oscilando na direção perpendicular ao escoamento, com o objetivo de analisar as mudanças que ocorrem na topologia das linhas baseadas no desprendimento de vórtices e estudar os coeficientes de arrasto $C_{d}$ e sustentação $C_{l}$ deste cilindro. O método numérico utilizado para solucionar as equações 
de Navier-Stokes para o caso bidimensional, é baseado na discretização de segunda ordem para as derivadas espaciais e o avanço no tempo é solucionado através do esquema de Adams-Bashforth. A malha utilizada é irregular e uniformemente espaçada ao redor do cilindro e estirada nas demais regiões. O código computacional é testado inicialmente para o caso em que o cilindro encontra-se em repouso para número de Reynolds $R e=185$, $R e=500$ e $R e=1000$. Para o cilindro oscilante, os coeficientes de arrasto e sustentação foram calculados para os mesmos números de Reynolds. Para $R e=185$, foi utilizada uma amplitude de oscilação $A=0,4$ para um intervalo de frequências $F$ entre 0,8 e 1,2. O fenômeno da atrelagem síncrona foi capturado pra valores de $F$ maiores do que 1 . Para $R e=500$ não foram efetuados os cálculos dos coeficientes de arrasto e sustentação, mas através do estudo da esteira de vórtices, percebeu-se que a atrelagem ocorre para $F$ entre 1,0 e 1,05, valor menor do que para o caso em que $R e=185$. Para o caso em que $R e=1000$ também não foram efetuados os cálculos dos coeficientes de arrasto e sustentação, e novamente através da análise do desprendimento de vórtices, pode-se perceber a ocorrência de atrelagem para valores de $F$ menores do que 1, isto é, entre 0,95 e 1 . Os resultados de Lu e Dalton foram validados com a utilização dos resultados experimentais obtidos por Gu, Chyu e Rockwell (GU; CHYU; ROCKWELL, 1994)

O trabalho desenvolvido por Liu, Zheng e Sung (LIU; ZHENG; SUNG, 1998) baseia-se na simulação tridimensional do escoamento incompressível turbulento. Os efeitos turbulentos foram estimados utilizando o modelo de turbulência $k-\omega$. Para validar o modelo de turbulência, foram efetuadas inicialmente simulações do escoamento em torno de um cilindro oscilante, e um estudo da esteira de von Kármán para número de Reynolds $R e$ igual a 100, 150 e 200. Para $R e=150$ foram efetuadas simulações com refinamento de malha. Os resultados para os seis tipos de malhas testados foram similares devido ao baixo número de Reynolds. A malha mais grossa utilizada tinha 64 pontos na vertical e na horizontal, e a malha mais fina continha 256 pontos, nas direções vertical e horizontal. Para $R e=100$, o coeficiente de pressão e o número de Strouhal alcançaram valores semelhantes a outros trabalhos experimentais. Os mesmos cálculos foram efetuados para $R e=200 \mathrm{e}$ comparados com outros sete trabalhos numéricos e quatro trabalhos experimentais.

Blackburn e Henderson (BLACKBURN; HENDERSON, 1999) estudaram o efeito da variação da frequência $F$, no escoamento de um fluido em torno de um cilindro com movimentação perpendicular à direção do escoamento. Para superar as dificuldades operacionais da simulação numérica, as simulações foram realizadas considerando-se escoamentos bidimensionais e limitados a um $R e=500$, com frequência de oscilação $F$ variável e amplitude igual a 0,25. Para solucionar as Equações de Navier-Stokes, foi utilizado um método baseado na discretização espacial em elementos espectrais e um esquema de discretização do tempo de segunda ordem. Para o caso em que o cilindro encontra-se em repouso, dois conceitos são utilizados para analisar o desprendimento de vórtices: o de que a continuidade exige que os pontos de separação e recolamento ocorram aos pares em caso de 
escoamento bidimensional ao longo do formato do corpo, e que separação e recolamento ocorrem nos pontos da superfície onde a vorticidade é nula. Foi efetuada a simulação com com cilindro em movimento, com uma frequência de oscilação entre $0,75<F<1,05$. Já era sabido que o desprendimento de vórtices se dá de maneiras diferentes para $F=0,875$ e $F=0,975$ e essas frequências foram escolhidas como aproximações iniciais. As simulações foram iniciadas com o campo de velocidade do escoamento em torno do cilindro em repouso e posteriormente com o cilindro em movimento. Os resultados são validados comparando-se com os resultados do trabalho de Gu, Chyu e Rockwell (GU; CHYU; ROCKWELL, 1994) e e por Lu e Dalton (LU; DALTON, 1996). O estudo das linhas de vorticidade e a mudança nos resultados com o aumento da frequência $F$ foram concordantes com os resultados disponíveis nos trabalhos citados. No trabalho de Blackburn e Henderson também foi feita uma análise do efeito da escolha das condições iniciais sobre resultados obtidos. Vários testes foram efetuados com variação do tempo de início de movimentação do cilindro. Considerando $T$ o período de desprendimento de vórtices para o caso em que o cilindro encontra-se fixo, foram testados os tempos iniciais $t_{0}$ igual a 0 , 0,25T, 0,5T e 0,75T. Para todas as frequências testadas os resultados apresentam uma esteira de von Kármán. Para a frequência menor, o tempo de transição para o estado periódico foi bem mais curto que para a frequência maior. Iniciando os cálculos para com as frequências $F=0,875$ e $F=0,975$, foram efetuados testes com aumento e diminuição das mesmas. O campo final de velocidades da frequência anterior foi reaproveitado para o cálculo da próxima frequência, com o ângulo de movimentação do cilindro e soluções ajustados. Isso foi feito com o intuito de imitar o comportamento de situações físicas onde há uma pequena variação na frequência a cada passo de tempo. É efetuada também uma análise da energia transferida em função da frequência $F$. Durante a mudança de frequências, pode-se perceber ramificações associadas as esteiras assimétricas. Para esses testes, foram utilizadas as frequências iniciais de $F=0,975$ e 0,875 com variação positiva e negativa de $\Delta F$, obtendo-se assim dois resultados diferentes para $F=0,89$, um onde o desprendimento de vórtices forma uma esteira de von Kármán, e outro onde há um desprendimento irregular a assimétrico de vórtices, inclusive com emissão dupla, onde encontra-se o desprendimento de vórtices acoplados e isolados. Para os testes efetuados com uma frequência $F=0,904$, a natureza da assimetria é bem diferente da encontrada anteriormente, e pode-se encontrar uma esteira completa de vórtices a cada oscilação do cilindro, que envolve vórtices isolados e vórtices acoplados. Portanto, os resultados encontrados sugerem que a descontinuidade na emissão dos vórtices é causada pela competição entre dois mecanismos de emissão desses vórtices. O trabalho de Blackburn e Henderson, no entanto, não reproduz totalmente o comportamento de experimentos de escoamentos em torno de cilindros com oscilação forçada, justificada pela restrição a oscilações simples, simulações bidimensionais e baixo número de Reynolds. Todavia, sugere-se que os resultados sejam utilizados para possíveis simulações tridimensionais. 
Lai e Peskin (LAI; PESKIN, 2000) propuseram um método de segunda ordem, baseado na filosofia das fronteiras imersas e efetuaram uma comparação da sua eficiência numérica com um método de fronteira imersa de primeira ordem. O caso teste é baseado na simulação do escoamento em torno de um cilindro de diâmetro 0,30. Foram efetuados testes para $R e=100, R e=150$ e $R e=200$, e os coeficientes de arrasto e sustentação, juntamente com o número de Strouhal foram calculados e comparados a resultados experimentais. Lai e Peskin encontraram valores para o coeficiente de arrasto $C_{d}$ variando entre 1, 4473 e 1,5406, coeficiente de sustentação $C_{l}$ variando entre 0,2829 e 0,3299 e Número de Strouhal variando entre 0,133 e 0,165. As principais diferenças entre os desempenhos do método de primeira e segunda ordem acontece quando há desprendimento alternado de vórtices a jusante do cilindro. Neste caso, o esquema de primeira ordem apresenta um número de Strouhal 20\% menor quando comparado aos resultados experimentais. Já o esquema de segunda ordem oferece resultados muito melhores quando comparado aos trabalhos experimentais. A principal vantagem do bom funcionamento deste método de segunda ordem é a possibilidade de aplicá-lo a valores mais altos para o número de Reynolds.

Analisando ainda escoamentos ao redor de cilindros, foram realizados diversos estudos sobre as vibrações induzidas por vórtices num com objetivo de melhorar os danos causados nas plataformas de extração em alto mar de indústrias petrolíferas. O trabalho de Cunff, Biolley, Fontaine, Étienne e Facchinetti (CUNFF, 2002) apresenta primeiramente uma revisão sobre o fenômeno de vibrações induzidas por vórtices e, logo depois, diversas aproximações são propostas para estudar as interações entre sólido e fluido. Uma primeira aproximação é baseada no modelo responsável pela estrutura, que é amplamente usado pela indústria para estimar o tempo de vida dos cabos e materiais. A segunda aproximação exige a resolução de uma equação estrutural no tempo através de uma equação que modela o fluido. A terceira aproximação envolve a resolução das Equações de NavierStokes. Foram apresentados também os resultados de um conjunto de experimentos em um cabo com vários diâmetros testados. O modelo responsável que calcula a vibração da estrutura está separado em duas aproximações: a primeira aproximação assume que o escoamento ao contrário do movimento é o mais perigoso e o que causa mais danos ao cilindro, e se restringe à análise desse deslocamento. A segunda aproximação consiste no cálculo da força de um fluido em modos independentes, desprezando as interações entre forças que se cruzam. A aproximação modal dá uma boa estimativa do desgaste e permite o estudo de um amplo número de casos mais facilmente. No entanto, o método apresenta algumas falhas, como o fato de ser limitado para as vibrações contra o sentido do escoamento, além de exigir que o modo da frequência seja perpendicular à corrente. Os vários códigos baseados na aproximação modal dependem de coeficientes empíricos e podem predizer diferentes amplitudes em um caso similar. O objetivo de um modelo de fluido consiste em reproduzir a força exercida pelo fluido na estrutura e a maneira como 
ela é influenciada pelo movimento dessa estrutura. De um ponto de vista estrutural, não são exigidos muitos detalhes na análise do fluido. Além disso, o esforço pode ser concentrado em um simples parâmetro (coeficiente de força) descrevendo fluido. Nesse artigo, o modelo utilizado foi um oscilador de esteira tridimensional, baseado num modelo que resume a natureza oscilatória da esteira de vórtice, governado pelas equações não lineares de Van der Pol's. A mais avançada aproximação é a computação de um problema acoplado, com um conjunto de equações para a estrutura e as equações de Navier-Stokes para fluidos, com um alto número de Reynolds. Nesse artigo é aplicado um método bidimensional que soluciona a equação subdividida em partes. Os estudos experimentais foram realizados em um tanque de teste com área de $24 \times 16 \mathrm{~m}$, com profundidade ajustável até $5 \mathrm{~m}$. A velocidade máxima é de $0,5 \mathrm{~m} / \mathrm{s}$. A profundidade utilizada foi de $3 \mathrm{~m}$, com velocidade variando entre 0,2 e $0,4 \mathrm{~m} / \mathrm{s}$. O diâmetro do cabo utilizado variou entre 5 e $21 \mathrm{~mm}$ de diâmetro, com número de Reynolds menor que $10^{4}$. Os resultados obtidos experimentalmente mostraram boas concordâncias com os resultados obtidos para perturbações multi-modais. Os resultados experimentais foram de considerável importância para garantir a validação das ferramentas numéricas utilizadas.

Nobari e Naderam (NOBARI; NADERAN, 2006) estudaram numericamente o escoamento bidimensional em torno de um cilindro oscilante para diferentes valores de frequência e amplitude. As equações que modelam o escoamento foram solucionadas utilizando o método de elementos finitos. Para possibilitar a simulação do movimento do cilindro, que ocorreu tanto na mesma direção do escoamento como na direção perpendicular ao mesmo, foi utilizado o esquema de movimentação de malha na formulação Euleriana-Lagrangeana Arbitrária. Através das simulações, foi estudado o desprendimento de vórtices para o caso em que o cilindro oscila na mesma direção do escoamento com $R e=300$ e para o caso em que o cilindro oscila na direção perpendicular ao mesmo, com $R e=100$. Também foi efetuado um estudo da ocorrência do fenômeno da atrelagem síncrona, juntamente com a influência do fenômeno no formato dos vórtices desprendidos.

Para simular numericamente o escoamento em torno de um cilindro oscilando na mesma direção do mesmo com $R e=200$, Al-Mdallal, Lawrence e Kocabiyik (M.ALMDALLAL; LAWRENCE; KOCABIYIK, 2007), utilizaram um método baseado em análise de Fourier espectral juntamente com aproximações por diferenças finitas. Os experimentos numéricos mostram o cilindro oscilando com amplitude $A=0,1$ ou $A=0,3$, com frequência de oscilação $F$ entre 0,5 e 3. Uma análise do desprendimento de vórtices e sua relação com os coeficientes de arrasto e sustentação foi efetuada juntamente com o estudo da ocorrência do fenômeno de atrelagem síncrona através dos modelos de Lissajous. As formações das curvas de coeficiente de sustentação $C_{l}$ foram analisadas e relacionadas com a atrelagem síncrona e utilizadas para as verificações dos resultados numéricos aqui obtidos pelo Método das Fronteiras Imersas. O fenômeno foi capturado para frequência de oscilação próxima de 2, tanto para oscilação com amplitude $A=0,1$ como para amplitude 
$A=0,3$.

\subsection{Considerações Finais}

Neste trabalho, são apresentados resultados de simulações numéricas do escoamento bidimensional em torno de um cilindro circular que pode estar em repouso ou movimentandose na mesma direção do escoamento, na direção perpendicular o rotacionando em torno no próprio eixo. Para isso, foi implementado um código baseado no método das Fronteiras Imersas. A revisão bibliográfica realizada aqui tem como objetivo apresentar estudos realizados de forma experimental e numérica de escoamentos em torno de cilindros e os resultados dos mesmos serão utilizados no capítulo de resultados para verificação e validação do código proposto. 


\section{Métodos}

Para simular o escoamento em torno de um cilindro circular em repouso ou oscilante para baixo número de Reynolds, torna-se necessário solucionar numericamente as equações que modelam este escoamento, ou seja, as Equações de Navier Stokes. Neste trabalho, a isso foi feito utilizando mo método das Fronteiras Imersas, que não necessita da utilização de uma malha numérica que se adapte ao contorno do corpo que serve como obstáculo ao escoamento. Este método baseia-se na discretização das equações por diferenças finitas. A atualização no tempo foi efetuada através de um método de Runge-Kutta de Quarta Ordem e o cálculo das derivadas espaciais foi realizado através do método de diferenças finitas compactas de alta ordem. Foi utilizada a formulação alternativa de Vorticidade-Velocidade, e para solucionar a equação de Poisson resultante, o método multigrid foi adotado. Para efetuar os cálculos do coeficiente de arrasto $C_{d}$ e do coeficiente de sustentação $C_{l}$, foi utilizada a técnica de volume de controle.Este capítulo dedica-se ao estudo e descrição de cada um desses métodos.

\subsection{Aproximação das Derivadas Espaciais por Dife- renças Finitas}

Para efetuar o cálculo das derivadas espaciais, são utilizadas diferenças finitas de alta ordem. De acordo com (FORTUNA, 2000) expressões de $O(\Delta x)^{2}$ para derivadas de ordem $m$ necessitam geralmente de $m+2$ pontos para serem calculadas. Assim, em geral, para uma fórmula de $O(\Delta x)^{p}$, para $p>1$, necessita-se $m+p$ pontos. As fórmulas de alta ordem, apesar de um aumento no custo computacional, destacam-se pela rapidez na convergência e pela diminuição do erro. A vantagem de utilizar diferenças finitas compactas está na 
alta ordem que elas apresentam, na redução do número de pontos a serem utilizados e na baixa dispersão e dissipação numérica. No entanto, a utilização de diferenças finitas compactas torna necessário resolver numericamente um sistema linear.

\subsubsection{Cálculo da Primeira Derivada}

Para o ponto no contorno, $i=1$, será adotada a aproximação descentrada de quinta ordem aplicada da seguinte forma:

$$
f_{1}^{\prime}+4 f_{2}^{\prime}=\frac{1}{24 . h}\left(-74 f_{1}+16 f_{2}+72 f_{3}-16 f_{4}-2 f_{5}\right)+O\left(h^{5}\right)
$$

Para o ponto próximo da parede, $i=2$, será adotada a aproximação descentrada de sexta ordem:

$$
f_{1}^{\prime}+6 f_{2}^{\prime}+2 f_{3}^{\prime}=\frac{1}{120 . h}\left(-406 f_{1}-300 f_{2}+760 f_{3}-80 f_{4}+30 f_{5}-4 f_{6}\right)+O\left(h^{6}\right)
$$

Para os pontos centrais adotou-se a seguinte aproximação

$$
f_{i-1}^{\prime}+3 f_{i}^{\prime}+f_{i+1}^{\prime}=\frac{1}{12 . h}\left(-f_{i-2}-28 f_{i-1}+28 f_{i+1}+f_{i+2}\right)+O\left(h^{6}\right)
$$

Para o caso $i=N$ e $i=N-1$ as aproximações são análogas às obtidas para os pontos $i=1$ e $i=2$ com inversão dos sinais. Para calcular todas a derivadas, há a necessidade de solucionar a equação $E f^{\prime}=G f$, com inversão de uma matriz tridiagonal, da forma: 
$\left[\begin{array}{cccccc}1 & 4 & & & & \\ 1 & 6 & 2 & & & \\ & & \ddots & & & \\ & & & 1 & 3 & 1 \\ & & & & \ddots & \\ & & & 2 & 6 & 1 \\ & & & & 4 & 1\end{array}\right]\left[\begin{array}{c}f_{1}^{\prime} \\ f_{2}^{\prime} \\ \vdots \\ f_{i}^{\prime} \\ \vdots \\ f_{N-1}^{\prime} \\ f_{N}^{\prime}\end{array}\right]=$

$$
\frac{1}{h}\left[\begin{array}{c}
\frac{1}{24}\left(-74 f_{1}+16 f_{2}+72 f_{3}-16 f_{4}+2 f_{5}\right) \\
\frac{1}{120}\left(-406 f_{1}-300 f_{2}+760 f_{3}-80 f_{4}+30 f_{5}-4 f_{6}\right) \\
\vdots \\
\frac{1}{12}\left(-f_{i-2}-28 f_{i-1}+28 f_{i+1}+f_{i+2}\right) \\
\vdots \\
\frac{1}{120}\left(406 f_{N}+300 f_{N-1}-760 f_{N-3}-30 f_{N-4}+4 f_{N-5}\right) \\
\frac{1}{24}\left(+74 f_{N}-16 f_{N-1}-72 f_{N-2}+16 f_{N-3}-2 f_{N-4}\right)
\end{array}\right]
$$

\subsubsection{Cálculo da Segunda Derivada}

Para o ponto no contorno, $i=1$, adotou-se a aproximação descentrada de quinta ordem, como segue abaixo:

$$
f_{1}^{\prime \prime}+137 f_{2}^{\prime \prime}=\frac{1}{120 . h}\left(9775 f_{1}-20285 f_{2}+11170 f_{3}-550 f_{4}-145 f_{5}+36 f_{6}\right)+O\left(h^{5}\right)
$$

Para o ponto próximo à parede, $i=2$, adotou-se a aproximação descentrada de sexta ordem, que fica da seguinte forma:

$$
f_{1}^{\prime \prime}+12 f_{2}^{\prime \prime}+3 f_{3}^{\prime \prime}=\frac{1}{360 . h}\left(4834 f_{1}-8424 f_{2}+1890 f_{3}-2320 f_{4}-810 f_{5}+216 f_{6}-26 f_{7}\right)+O\left(h^{6}\right)
$$

Nos pontos centrais foi aplicada a seguinte aproximação:

$$
f_{i-1}^{\prime \prime}+11 f_{i}^{\prime \prime}+2 f_{i+1}^{\prime \prime}=\frac{1}{4 . h^{2}}\left(3 f_{i-2}+48 f_{i-1}-102 f_{i}+48 f_{i+1}+3 f_{i+2}\right)+O\left(h^{6}\right)
$$

Para o caso $i=N$ e $i=N-1$ as aproximações são análogas as obtidas para os pontos $i=N$ e $i=N-1$. A equação a ser resolvida agora é $H f^{\prime \prime}=I f$, que resulta no sistema: 


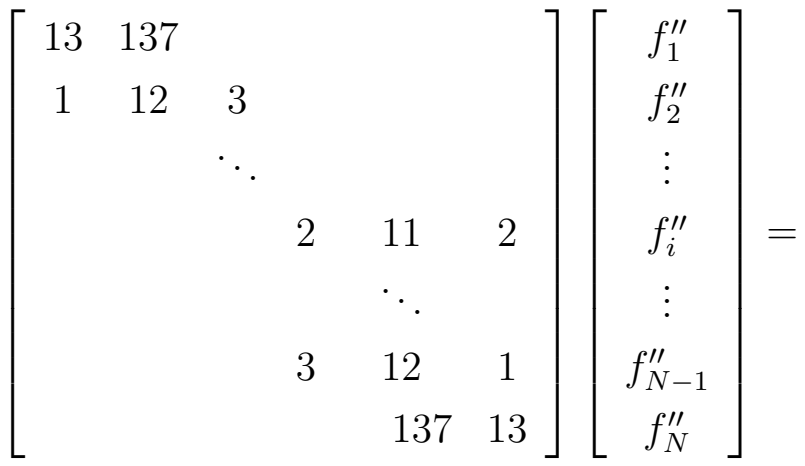

$$
\begin{aligned}
& \frac{1}{h^{2}}\left[\begin{array}{c}
\frac{1}{120}\left(9775 f_{1}-20285 f_{2}+11170 f_{3}-550 f_{4}-145 f_{5}+36 f_{6}\right) \\
\frac{1}{360}\left(4834 f_{1}-8424 f_{2}+1890 f_{3}+2320 f_{4}-810 f_{5}+216 f_{6}-26 f_{7}\right) \\
\vdots \\
\frac{1}{4}\left(3 f_{i-2}+48 f_{i-1}-102 f_{i}+48 f_{i+1}+3 f_{i+2}\right) \\
\vdots \\
\frac{1}{360}\left(4834 f_{N}-8424 f_{N-1}+1890 f_{N-2}+2320 f_{N-3}-810 f_{N-4}+216 f_{N-5}-26 f_{N-6}\right) \\
\frac{1}{120}\left(9775 f_{N}-20285 f_{N-1}+11170 f_{N-2}-550 f_{N-3}-145 f_{N-4}+36 f_{N-5}\right)
\end{array}\right]
\end{aligned}
$$

\subsection{Derivadas Temporais e o Método de Runge- Kutta}

Para efetuar as atualizações no tempo, é utilizado um Método de Runge-Kutta de Quarta Ordem. A escolha desse método se justifica pela sua simplicidade, alta precisão e versatilidade (LAMBERT, 1973). Os métodos de Runge-Kutta são muito utilizados, principalmente porque podem ser expressos por uma seqüência de fórmulas explícitas, mas com diversos estágios, de modo a se obter uma maior ordem de aproximação. A idéia básica deste tipo de método é definir que o comportamento da variável dependente, no passo em questão, é dada por uma média ponderada de variações desta variável, calculadas com avaliações diferentes da função derivada. Sua implementação em computadores também é extremamente simples.

O método utilizado neste trabalho funciona em quatro passos, de acordo com as equações abaixo:

$$
\begin{gathered}
\Omega^{*}=\Omega^{n}+\frac{\Delta t}{4} f\left(t^{n}, \Omega^{n}\right) \\
\Omega^{* *}=\Omega^{n}+\frac{\Delta t}{3} f\left(t^{n}+\frac{1}{4}, \Omega^{n}\right)
\end{gathered}
$$




$$
\begin{gathered}
\Omega^{* * *}=\Omega^{n}+\frac{\Delta t}{2} f\left(t^{n}+\frac{1}{3}, \Omega^{* *}\right) \\
\Omega^{(n+1)}=\Omega^{n}+\Delta t f\left(t^{n}+\frac{1}{2}, \Omega^{* * *}\right)
\end{gathered}
$$

\subsection{Resolução da Equação de Poisson e Método Mul- tigrid}

Para a resolução da equação de Poisson (3.13), foi utilizado um método multigrid. Este método foi inicialmente proposto por Brandt (BRANDT, 1977), e é o mais significante desenvolvimento em análise numérica dos últimos trinta anos, tendo grande impacto na Dinâmica dos Fluidos Computacional. O método era aplicado primeiramente na aproximação de soluções para equações diferenciais parciais elípticas. Mais tarde, o método foi também utilizado na solução de sistemas não-lineares e outros tipos de equações. Sua principal vantagem é a rápida convergência. Todavia, ele pode exigir implementações específicas para cada tipo de problema a ser estudado. O método multigrid é mais eficiente computacionalmente por resolver equações diferenciais parciais elípticas discretizadas em $N$ pontos em $N \log N$ operações. Neste trabalho, de acordo com (SOUZA, 2003), o algoritmo adotado é o esquema de aproximação total FAS (Full Approximation Scheme), e será utilizado um ciclo V, com quatro malhas. Pode-se escrever a equação de Poisson da forma:

$$
\nabla^{2} v=g
$$

onde $\nabla^{2}$ é o operador laplaciano, $v$ é a velocidade $V_{k}$ e $g$ são os termos fonte da equação. Em cada malha, a equação é resolvida utilizando-se um método de sobre relaxação sucessiva por linha (LSOR-Line Sucessive Over Relaxation). Quando se efetua a mudança da malha mais grossa para a malha mais fina, o fator de relaxação utilizado deve ser igual a 1. Se este valor não for aplicado, não haverá a suavização das componentes de alta frequência do erro, que é a característica principal desse método.

As aproximações adotadas pelo LSOR, para a direção $x$ são dadas por:

$$
\begin{gathered}
\left.\frac{\partial^{2} v}{\partial x^{2}}\right|_{2}=\frac{10 v_{1}-15 v_{2}-4 v_{3}+14 v_{4}-6 v_{5}+v_{6}}{12 \Delta x^{2}}+O\left(\Delta x^{4}\right) \\
\left.\frac{\partial^{2} v}{\partial x^{2}}\right|_{3 \leq i \leq i_{\text {max }}-2}=\frac{-v_{i-2}+16 v_{i-1}-30 v_{i}+16 v_{i+1}-v_{i+2}}{12 \Delta x^{2}}+O\left(\Delta x^{4}\right)
\end{gathered}
$$




$$
\left.\frac{\partial^{2} v}{\partial x^{2}}\right|_{i_{\max }-1}=\frac{10 v_{i_{\max }}-15 v_{i_{\max }-1}-4 v_{i_{\max }-2}+14 v_{i_{\max }-3}-6 v_{i_{\max }-4}+v_{i_{\max }-5}}{12 \Delta x^{2}}+O\left(\Delta x^{4}\right)
$$

Para a direção $y$, as aproximações ficam da forma:

- $\operatorname{para} j=2$

$$
\left.\frac{\partial^{2} v}{\partial y^{2}}\right|_{2}+\left.4 \frac{\partial^{2} v}{\partial y^{2}}\right|_{3}=\frac{254 v_{1}-432 v_{2}+162 v_{3}+16 v_{4}}{36 \Delta y^{2}}+O\left(\Delta y^{5}\right)
$$

- $\operatorname{para} 3 \leq j \leq j_{\max }-2$

$$
\left.2 \frac{\partial^{2} v}{\partial y^{2}}\right|_{j-1}+\left.11 \frac{\partial^{2} v}{\partial y^{2}}\right|_{j}+\left.2 \frac{\partial^{2} v}{\partial y^{2}}\right|_{j+1}=\frac{3 v_{j-2}+48 v_{j-1}-102 v_{j}+48 v_{j+1}+3 v_{j+2}}{4 \Delta y^{2}}+O\left(\Delta y^{6}\right)
$$

- $\operatorname{para} j=j_{\max }-1$

$$
\left.\frac{\partial^{2} v}{\partial y^{2}}\right|_{j_{\max }-1}=\frac{v_{j_{\max }-2}-2 v_{j_{\max }-1}+v_{j_{\max }}}{\Delta y^{2}}+O\left(\Delta y^{2}\right)
$$

- $\operatorname{para} j=j_{\max }$

$$
\left.\frac{\partial^{2} v}{\partial y^{2}}\right|_{j_{\max }}=-\frac{7 v_{j_{\max }}+8 v_{j_{\max }-1}-v_{j_{\max }-2}}{2 \Delta y^{2}}+\frac{3}{\Delta y} \frac{\partial v}{\partial y}+O\left(\Delta y^{2}\right)
$$

onde $i_{\text {max }}$ e $j_{\text {max }}$ correspondem aos pontos localizados nos contornos nas direções longitudinal e normal à parede, respectivamente. Estes valores variam de malha para malha. Com estas aproximações constrói-se uma matriz pentadiagonal que é resolvida para cada coluna $x$ do domínio. A solução dessa matriz para todas as colunas do domínio é chamada de iteração.

A essência do método multigrid é efetuar os cálculos passando de uma malha mais fina para uma malha mais grossa, com o objetivo de eliminar as altas frequências de erro, e depois retornar a solução para a malha mais fina. Assim, tomando-se $h$ como o sendo a distância entre dois pontos da malha mais fina, realiza-se duas iterações nesta malha, da forma:

$$
\nabla^{2} v_{h}=g_{h}
$$

Após essas iterações, é calculado o resíduo $\left(d_{h}\right)$ da forma

$$
d_{h}=g_{h}-\nabla^{2} v_{h}
$$


Para realizar a passagem de valores das variáveis de uma malha mais fina $(h)$ para uma mais grossa $(2 h)$, efetua-se uma operação denominada restrição. Os termos que sofrem esta operação são:

$$
\begin{gathered}
v_{h}^{i} \Rightarrow v_{2 h}^{0} \\
d_{h}^{i} \Rightarrow d_{2 h}^{0}
\end{gathered}
$$

onde (3.23) é a equação de Straight Injection (SI), ou seja, significa que os valores da variável na malha mais fina são passados para a malha mais grossa diretamente, sem efetuar o cálculo em média. (3.24) é a equação de Full Weight (FW), que representa a ponderação dos valores da variável da malha mais fina para a malha mais grossa.

Em seguida, o cálculo do termo fonte para a segunda malha (2h) é efetuado da forma:

$$
g_{2 h}=d_{2 h}^{0}+\nabla^{2} d_{2 h}^{0}
$$

Novamente, são realizadas duas iterações na segunda malha $(2 h)$ através de:

$$
\nabla^{2} v_{2 h}=g_{2 h}
$$

O resíduo $\left(d_{2 h}\right)$ desta malha é calculado com:

$$
d_{2 h}=g_{2 h}-\nabla^{2} v_{2 h}
$$

e assim sucessivamente, até a malha mais grossa (8h) onde são realizadas 10 iterações:

$$
\nabla^{2} v_{8 h}=g_{8 h}
$$

Para retornar à malha mais fina, primeiramente é calculada a correção da malha mais grossa:

$$
\operatorname{corr}_{8 h}=v_{8 h}^{i}+v_{8 h}^{0}
$$

Para passar os valores da variável corr $_{8 h}$ da malha mais grossa para a malha mais fina, faz-se uma interpolação bilinear destes valores:

$$
\operatorname{corr}_{8 h} \Rightarrow \operatorname{corr}_{4 h}
$$

Em seguida, os novos valores do termo $v_{4 h}$ são calculados da forma: 


$$
v_{4 h}=v_{4 h}^{i}+\operatorname{corr}_{4 h}
$$

Realiza-se uma iteração na terceira malha $(4 h)$ :

$$
O v_{4 h}=f(4 h)
$$

e assim sucessivamente até a iteração na malha mais fina $(h)$

$$
O v_{h}=g_{h}
$$

O número de ciclos $\mathrm{V}$ utilizados para a solução da equação depende do valor do resíduo na malha mais fina. Se este valor for menor que um valor de referência adotado, o procedimento é interrompido e a aproximação é tomada como resposta. O valor de referência adotado neste trabalho foi $10^{-9}$.

\subsection{O Método das Fronteiras Imersas}

O termo Método das Fronteiras Imersas designa uma classe de métodos onde os cálculos são efetuados numa malha cartesiana que não se adapta à forma do corpo que serve como obstáculo ao escoamento (MEULEN, 2006). As condições de contorno na superfície do corpo não são impostas diretamente. Ao invés disso, um termo extra chamado de termo forçante é adicionado às equações que modelam o escoamento. Os Métodos de Fronteiras Imersas podem ser classificados em duas classes distintas: a primeira trata de fronteiras imersas móveis e é adequado para problemas de interação entre fluido e estrutura, e a segunda enfoca as fronteiras imersas complexas e estáticas.

O Método de Fronteiras Imersas foi proposto inicialmente por Charles S. Peskin (PESKIN, 2002), que desenvolveu uma técnica em 1972 para estudar o escoamento de sangue em sistemas cardíacos. Sua formulação consiste em uma malha cartesiana com coordenadas Eulerianas fixas no espaço que são utilizadas para solucionar as equações que modelam o escoamento, e uma malha curvilínea com sistema da coordenadas Lagrangeanas móveis com velocidade local de escoamento, que é anexa as fronteiras elásticas (as paredes do coração). A informação sobre a posição da fronteira e a força elástica que ela exerce sobre o fluido é então transferida para a malha cartesiana com o objetivo de obter a solução do escoamento. Para projetar a força na malha, uma função delta suave (função de distribuição) é utilizada.

O sucesso do método estendeu-se, e na década de oitenta as aproximações por Fronteiras Imersas foram aplicadas em sólidos com fronteiras não deformáveis. Essa adaptação foi tentada primeiramente através da diminuição da deformação das fibras elásticas do modelo de fronteiras imersas. Todavia os resultados não foram satisfatórios para o esco- 
amento ao redor de corpos rígidos. Alguns métodos foram propostos durante a década de noventa, no entanto sem bons resultados, pois as forças contínuas não representam adequadamente as formas do contorno.

Dessa forma, o campo de estudo do Método de Fronteiras Imersas concentra-se principalmente em escoamentos com fronteiras móveis e ao redor de geometrias complexas. O desenvolvimento de métodos computacionais robustos como alternativa para as técnicas que utilizam malhas elásticas, ou seja, malhas que se adaptam ao contorno do sólido que serve com obstáculo ao escoamento, é o principal objetivo da comunidade científica que estuda esse método.

\subsubsection{Método das Fronteiras Imersas: Vantagens e Desvanta- gens}

Esta subseção destina-se a esclarecer e avaliar algumas vantagens e desvantagens do método das Fronteiras Imersas. De acordo com as declarações anteriores, fica claro que impor condições de contorno não é tão simples quando as malhas cartesianas são utilizadas e perceber a influência do tratamento do contorno nas propriedades de exatidão e conservação do esquema numérico não é uma tarefa tão óbvia. Uma das principais características dos Métodos de Fronteira Imersa é a utilização de malhas cartesianas. Em geral, uma malha é considerada de boa qualidade quando tem o menor número de pontos possível e ainda sim fornece uma solução computacional aceitável. A aplicação dessa malha resultará, com o avanço no tempo, numa solução com boa exatidão. Uma malha cartesiana de alta qualidade que tenha uma intersecção com as fronteiras imersas é razoavemente simples de ser gerada para algumas geometrias, mesmo que complexas, e para corpos em movimento. Métodos que utilizam malhas que se adaptam à forma do corpo geralmente resultam em problemas quando tratam de geometrias complexas ou em movimento, mesmo que a malha aplicada seja não estruturada.

Gerar uma malha estruturada de alta qualidade de acordo com corpos com geometrias complexas pode ser muito trabalhoso se o algoritmo utilizado não leva em consideração as formas pontiagudas, rombudas, ou buracos existentes na geometria de corpos irregulares. Além disso, obter malhas de qualidade pode exigir uma maior interação humana, o que pode aumentar o tempo de processo em até $25 \%$ do tempo total de computação. Malhas não estruturadas se adaptam melhor a situações que envolvem corpos com formas complexas, mas necessitam de uma quantidade de tempo de processamento e memória substancialmente maior para sua geração e armazenamento se comparada a malhas estruturadas. Malhas cartesianas, todavia, podem ser obtidas de maneira mais rápida e fácil quando são utilizados geradores de malhas automáticos, sem a necessidade de ser programada manualmente durante o estudo. Ao contrário de malhas que se adaptam à forma do corpo, as malhas cartesianas não são afetadas significantemente pela alta complexidade 
na forma dos corpos. Em vários casos, o refinamento local nas malhas pode reduzir tanto o custo computacional como o custo de armazenamento de memória envolvido na geração da malha, o que torna as malhas cartesianas, neste caso, mais atrativas do que as malhas não estruturadas.

No caso de simulações de escoamento que envolvam fronteiras móveis, como as deformações que ocorrem durante a interação fluido-estrutura no choque de um corpo em queda livre com o chão, a malha tem que ser gerada ou movimentada a cada passo de tempo, além de ser necessário considerar a solução anterior na nova malha. Isso aumenta não só o custo computacional como também pode piorar a simplicidade, exatidão e estabilidade do método.

Assim, uma das principais vantagens do Método de Fronteiras Imersas é a utilização de malhas cartesianas fixas, o que torna a aplicação em problemas de escoamento com fronteiras móveis muito mais simples, sem a necessidade de gerar a malha novamente a cada passo no tempo. Esta é uma das causas que fazem do método das Fronteiras Imersas computacionalmente mais robusto se comparado a outros métodos que utilizam malhas que se adaptam ao corpo. Outra vantagem da malha cartesiana em relação às malhas que se adaptam ao formato do corpo é que o número de operações efetuadas por ponto da malha é significantemente baixo. Isso é válido tanto para as malhas estruturadas como para as malhas não estruturadas.

Quando uma malha curvilínea, que se adapta à forma do corpo, é aplicada, têm-se duas maneiras de calcular as variáveis de escoamento nas células. Uma é transformar o domínio físico em um domínio computacional através de transformação de coordenadas, solucionar a equação e retornar a solução para o domínio físico. A outra maneira é não utilizar de um domínio computacional, o que exige o cálculo do fluxo nas direções $X, Y$ e $Z$ em cada célula que está desalinhada em relação ao eixo das coordenadas, exigindo rotações locais. Outra vantagem do método de fronteiras imersas é justamente não necessitar desse número extra de operações, nem de rotações locais.

O método de Fronteiras Imersas também apresenta vantagens no que diz respeito a malhas cartesianas não estruturadas. Uma delas é o aumento na rapidez computacional aplicando técnicas de iteração por linha ou método de geometria multigrid. Mesmo que com menos simplicidade, essas técnicas podem ser também aplicadas em malhas não estruturadas.

Apesar de tantos atrativos numéricos, o método das Fronteiras Imersas também tem algumas desvantagens. Foi mencionado anteriormente que o tratamento das condições de contorno não é tão simples como para esse método, mas o principal problema é que o tamanho da malha cartesiana, ou seja, seu número total de pontos ou células, cresce mais rapidamente com o aumento do número de Reynolds do que no caso em que se utiliza malhas que se adaptam ao formato do corpo. Isso decorre do fato de existir alinhamento no entre as linhas da malha e a superfície do corpo em malhas adaptativas, o que resulta 
num melhor controle da resolução da malha na camada limite, o que não acontece no caso em que a malha aplicada é cartesiana.

O problema não é tão ruim quanto parece, desde que uma quantia substancial de pontos da malha sejam internos ao corpo que serve como obstáculo para o escoamento, onde as equações que modelam o escoamento precisam ser solucionadas (dependendo do tipo de método de Fronteiras Imersas aplicado).

\subsubsection{Formulação}

Como já citado anteriormente, neste estudo as equações que modelam o escoamento são as de Navier-Stokes para fluidos incompressíveis, com densidade e viscosidade constante. Elas são constituídas pela equação do momento para os componentes de velocidade $(u, v)$ na direção $x$ e $y$, dadas da seguinte forma:

$$
\begin{aligned}
& \frac{\partial u}{\partial t}+u \frac{\partial u}{\partial x}+v \frac{\partial u}{\partial y}=-\frac{\partial p}{\partial x}+\frac{1}{R e} \nabla^{2} u+F_{x} \\
& \frac{\partial v}{\partial t}+u \frac{\partial v}{\partial x}+v \frac{\partial v}{\partial y}=-\frac{\partial p}{\partial y}+\frac{1}{R e} \nabla^{2} v+F_{y}
\end{aligned}
$$

juntamente com a equação de continuidade:

$$
\frac{\partial u}{\partial x}+\frac{\partial v}{\partial y}=0
$$

onde $p$ é o termo pressão e $\nabla^{2}$ é dado por:

$$
\nabla^{2}=\frac{\partial^{2}}{\partial x^{2}}+\frac{\partial^{2}}{\partial y^{2}}
$$

e $F_{x}$ e $F_{y}$ são os termos forçantes introduzidos nas equações para a utilização do método de fronteiras imersas.

Todas as variáveis utilizadas acima estão na forma adimensional, que em formato dimensional são representadas por

$$
\begin{gathered}
x=\frac{x^{*}}{D^{*}} \\
y=\frac{y^{*}}{D^{*}} \\
u=\frac{u^{*}}{U_{\infty}^{*}} \\
t=\frac{t^{*} U_{\infty}^{*}}{D^{*}}
\end{gathered}
$$




$$
R e=\frac{U_{\infty}^{*} D^{*}}{\nu^{*}}
$$

onde Re é o número de Reynolds e os termos assinalados estão na forma adimensional. Além disso, $D^{*}$ é o diâmetro do cilindro, $U_{\infty}^{*}$ é a velocidade do escoamento livre e $\nu^{*}$ é o termo de viscosidade cinemática. A formulação vorticidade-velocidade é tomada como:

$$
\frac{\partial \omega_{z}}{\partial t}=-u \frac{\partial \omega_{z}}{\partial x}-v \frac{\partial \omega_{z}}{\partial y}+\frac{1}{R e} \nabla^{2} \omega_{z}+\frac{\partial F_{x}}{\partial y}+\frac{\partial F_{y}}{\partial x}
$$

Tomando a definição de vorticidade e as equações de conservação de massa, pode-se obter a equação de Poisson para a componente de velocidade $v$ :

$$
\nabla^{2} v=\frac{\partial v^{2}}{\partial x^{2}}+\frac{\partial v^{2}}{\partial y^{2}}=-\frac{\partial \omega_{z}}{\partial x}
$$

As equações que modelam o escoamento são complementadas pelas especificação das condições de contorno. Na saída do escoamento, todas as segundas derivadas de todas as variáveis dependentes foram tomadas como nulas.

O cálculo foi feito em uma malha ortogonal uniforme. A entrada do fluido no domínio computacional ocorre em $x=x_{0}$ e a fronteira de saída em $x=x_{\max }$. Na fronteira de entrada $\left(x=x_{0}\right)$, os componentes de velocidade e vorticidade são especificados. No contorno superior $\left(y=y_{\max }\right)$ e inferior $\left(y=y_{0}\right)$, as derivadas de $v$ na direção $y$ também são tomadas como nulas. Três regiões de amortecimento foram utilizadas na simulação, regiões estas que impedem o rebatimento de perturbações do escoamento nos contornos, o que afetaria o desprendimento natural de vórtices. Para evitar que isso aconteça, a expressão de vorticidade é multiplicada em cada passo de integração por uma função rampa, que varia suavemente entre 0 e 1 . Assim, as componentes de vorticidade serão tomadas da seguinte maneira:

$$
\omega_{z}(x, y)=f_{2}(x) \omega(x, y, t)
$$

onde $\omega(x, y, t)$ é a componente de vorticidade perturbada e $f_{2}(x)$ representa a função rampa. A implementação da função rampa na direção $x$, segundo Souza (SOUZA, 2005), é dada da seguinte forma:

$$
f_{2}(x)=f(\varepsilon)=1-6 \varepsilon^{5}+15 \varepsilon^{4}-10 \varepsilon^{3}
$$

onde $\varepsilon=\frac{\left(i-i_{3}\right)}{i_{4}-i_{3}}$ para $i \leq i \leq i_{4}$. Os pontos $i_{3}$ e $i_{4}$ correspondem às posições $x_{3}$ e $x_{4}$ do escoamento, respectivamente e $x_{\max }$ foi ser especificado. A zona de amortecimento na direção $x$ tem uma malha de 30 pontos na direção $x$ e 20 pontos na direção $y$. Entre a zona de segurança e a fronteira, tem-se um espaçamento de 10 pontos na malha. As diferenças finitas de sexta ordem descritas anteriormente foram utilizadas na discretização 
das derivadas espaciais. A Equação de Poisson foi solucionada utilizando-se o esquema de aproximação total multigrid (Full Approximation Scheme).

Segundo Souza (SOUZA, 2005), as equações para o cálculo das forças de contorno são tomadas da seguinte forma:

$$
\begin{aligned}
& F_{x}(i, j)=\alpha u(i, j) \delta(i, j) \\
& F_{y}(i, j)=\alpha v(i, j) \delta(i, j)
\end{aligned}
$$

$\operatorname{com} \delta(i, j)=0$ fora da região de fronteiras imersas e $\delta(i, j)=1$ no contorno e internamente à fronteira imersa. A constante $\alpha$ usada para calcular as forças é tomada como negativa, e neste trabalho terá o valor de $\alpha=-R e$.

Após o cálculo dos valores de $F_{x}$ e $F_{y}$, são calculadas as suas derivadas nas direções $y$ e $x$. A velocidade $v$ é encontrada através da solução numérica da equação (3.44) e a velocidade $u$ é encontrada solucionando-se a equação (3.36). Após isso, os valores das componentes de velocidade são verificados no interior da fronteira imersa. Se estes valores estão abaixo de um valor pré-determinado, um novo passo de integração pode ser utilizado.

Assim, o algoritmo a cada passo do método de Runge-Kutta para a solução das Equações de Navier-Stokes com o método de Fronteiras Imersas pode ser escrito da seguinte forma:

1. Calcular as derivadas espaciais da equação de transporte da vorticidade;

2. Calcular os termos forçantes $F_{x}$ e $F_{y}$;

3. Calcular o rotacional do termo forçante;

4. Integrar a equação de transporte e vorticidade em cada passo do esquema usando os valores obtidos nos passos 1 e 3 ;

5. Calcular a velocidade $v$ através da equação de Poisson;

6. Calcular a velocidade $u$ através da equação da continuidade;

7. Verificar os valores das componentes de velocidades nas fronteiras imersas, se estiverem acima de um valor pré-determinado, continua e volta para o passo 2.

O esquema acima continua até uma solução estável ou periódica seja encontrada. 


\subsection{Cálculo dos Coeficientes de Arrasto e Sus- tentação utilizando a Técnica de Volume de Con- trole}

Para efetuar os cálculos do coeficiente de arrasto $C_{d}$ e do coeficiente de sustentação $C_{l}$ foi implementada uma rotina baseada na técnica de Volume de Controle. Este método é baseado na determinação de um volume arbitrário no espaço onde há escoamento de fluido. O contorno geométrico do volume de controle é chamado de superfície de controle. Neste trabalho, a superfície de controle é um retângulo com arestas fixas em torno do cilindro que serve de obstáculo ao escoamento. A figura 3.1 ilustra o perfil da superfície de controle adotada nas implementações.

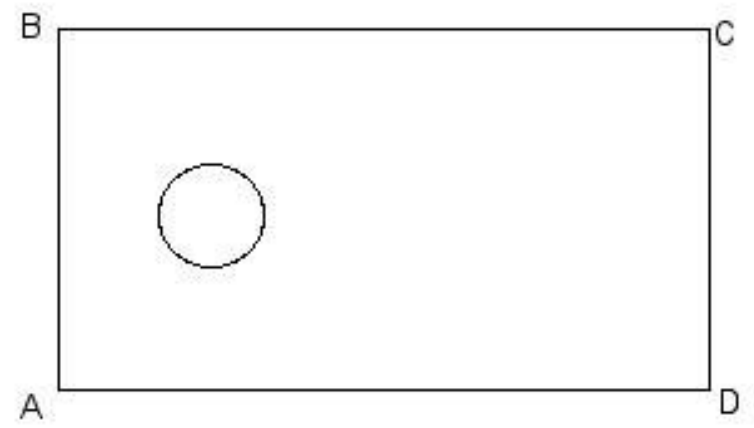

Figura 3.1: Superfície de controle adotada.

Os termos temporais $\frac{\partial}{\partial t}$, os termos convectivos $\vec{u} \nabla \vec{u}$, os termos difusivos $\nabla^{2}$ e os termos de pressão $P$ foram implementados separadamente. Os termos convectivos, difusivos e de pressão são calculados em cada uma das arestas do retângulo e as integrais foram solucionadas utilizando a Regra do Trapézio.

O coeficiente de arrasto $C_{d}$ e o coeficiente de sustentação $C_{l}$ foram calculados da seguinte forma:

$$
\begin{aligned}
C_{d} & =-2 \iint\left[\frac{\partial u}{\partial t}+u \frac{\partial u}{\partial x}+v \frac{\partial u}{\partial y}+\frac{\partial p}{\partial x}-\frac{1}{R e}\left(\frac{\partial^{2} u}{\partial x^{2}}+\frac{\partial^{2} u}{\partial y^{2}}\right)\right] d x d y \\
C_{l} & =-2 \iint\left[\frac{\partial v}{\partial t}+u \frac{\partial v}{\partial x}+v \frac{\partial v}{\partial y}+\frac{\partial p}{\partial y}-\frac{1}{R e}\left(\frac{\partial^{2} v}{\partial x^{2}}+\frac{\partial^{2} v}{\partial y^{2}}\right)\right] d x d y
\end{aligned}
$$




\subsection{Considerações Finais}

Neste capítulo foram apresentados os métodos utilizados na resolução numérica das Equações de Navier Stokes e na formulação do Método das Fronteiras Imersas. O próximo capítulo mostra a verificação e validação dos resultados numéricos obtidos com a simulação numérica do escoamento em torno de um cilindro circular. Foram simulados os casos em que o cilindro encontra-se em repouso ou oscilando na mesma direção, na direção paralela ao escoamento, ou ainda rotacionando em torno do próprio eixo. 


\section{Resultados}

Neste capítulo são apresentadas a verificação e a validação do código implementado. As simulações foram realizadas para o escoamento em torno do cilindro utilizando uma malha cartesiana regular contendo 641 pontos na direção horizontal e 497 pontos na direção vertical. O cilindro centrado no ponto com coordenadas $x=7$ e $y=7,5$ e raio igual a 1. O tempo de processamento de cada um dos testes foi em torno de 48 horas. Foram simuladas situações em que o cilindro encontrava-se em repouso ou com oscilação. Três tipos de oscilação foram testadas: oscilação na mesma direção do escoamento, oscilação na direção perpendicular ao escoamento e oscilação angular. A movimentação do cilindro na mesma direção do escoamento foi implementada segundo a equação (4.1):

$$
x=x_{0}+A \cdot F \cdot \cos (t)
$$

onde $C(x, y)$ é a posição do centro do cilindro, $A$ é amplitude de oscilação do cilindro, $F$ é a razão entre a frequência de oscilação e a frequência natural de desprendimento de vórtices do cilindro e $t$ é o tempo.

Da mesma forma, para o caso em que o cilindro oscila na direção perpendicular ao escoamento, o movimento é implementado de acordo com a equação (4.2):

$$
y=y_{0}+A \cdot F \cdot \cos (t)
$$

A equação que modela a rotação do cilindro em torno do próprio eixo com um ângulo de amplitude $\theta$ e uma frequência de oscilação $f$ foi implementada da seguinte forma:

$$
r o t=\theta \pi \cdot f \cdot \cos (2 \pi f t)
$$


onde $\theta$ é o deslocamento angular máximo e $t$ é o tempo em iterações.

O estudo dos casos em que o cilindro encontra-se estacionário ou oscilando na mesma direção do escoamento ou oscilando na direção perpendicular ao escoamento, ou rotacionando em torno do próprio eixo são mostrados nas subseções que seguem.

\subsection{Escoamento em torno do cilindro estacionário}

Para verificar os resultados das simulações do escoamento em torno de um cilindro estacionário foram utilizados os resultados fornecidos por Lai e Peskin (LAI; PESKIN, 2000) e Choi et al. (CHOI, 2007). As simulações foram efetuadas para $R e=100$ e a comparação entre os resultados obtidos é feita na tabela 4.1. Pode-se perceber que o presente método forneceu um ótimo resultado. A figura 4.1 mostra as curvas obtidas para os coeficientes de arrasto $C_{d}$ e de sustentação $C_{l}$. Pode-se perceber uma pequena discrepância no valor do coeficiente de arrasto $C_{d}$ fornecido pelo presente trabalho quando comparado ao trabalho de Choi et al., o que não acontece quando comparado ao trabalho de Lai e Peskin.

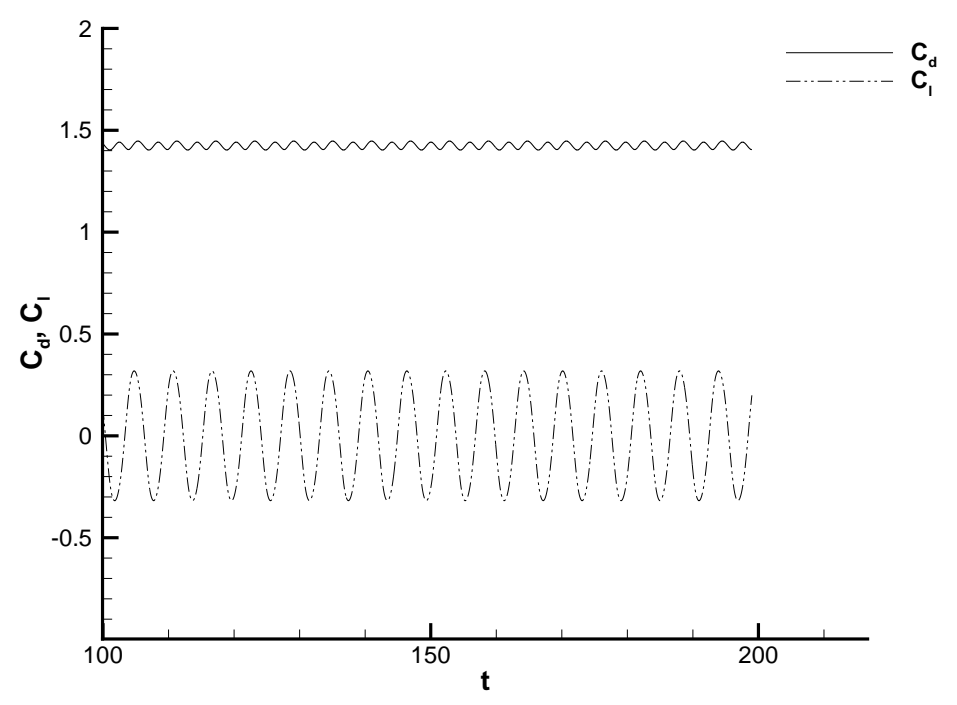

Figura 4.1: Coeficientes de arrasto e sustentação para $R e=100$ quando o cilindro está em repouso.

A figura 4.2 mostra os contornos de vorticidade para o escoamento em torno do cilindro com $R e=100$.

Para comparar os resultados fornecidos pelo Método das Fronteiras Imersas implementados neste trabalho com os resultados obtidos por Liu, Zheng e Sung (LIU; ZHENG; SUNG, 1998), foi simulado o escoamento em torno do cilindro estacionário com $R e=200$.

A figura 4.3 mostra as curvas do coeficiente de arrasto $C_{d}$ e do coeficiente de sustentação $C_{l}$ para o escoamento com $R e=200$. Obtidos os valores máximos de 1,39 e 


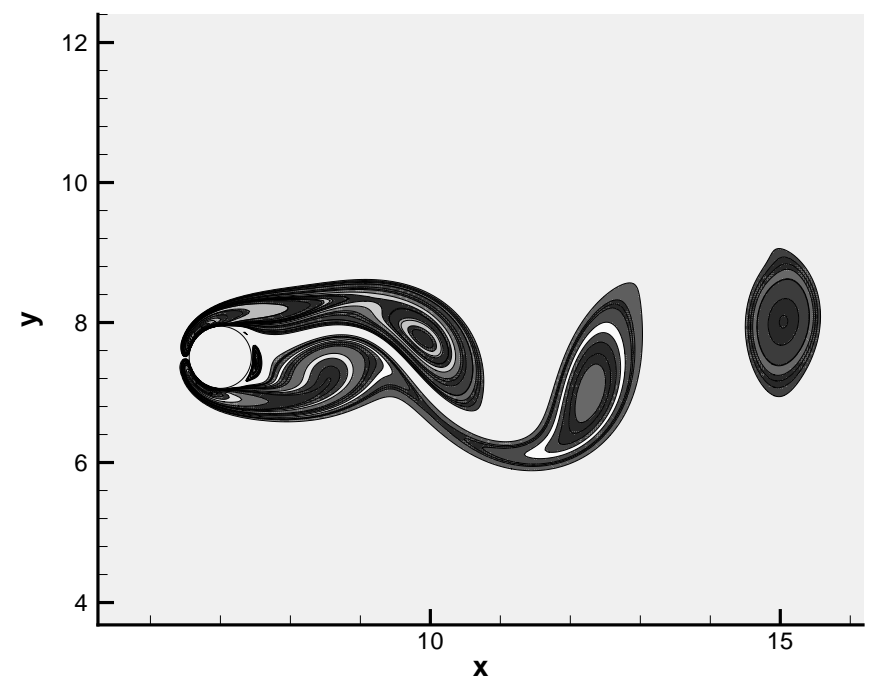

Figura 4.2: Contorno de vorticidade para $R e=100$ quando o cilindro está em repouso.

Tabela 4.1: Comparação do $C_{d}$ e $C_{l}$ máximo para $R e=100$ e para o cilindro em repouso.

\begin{tabular}{l|c|c|c}
\hline \hline & $C_{d}$ & $C_{l}$ & \\
\hline \hline & & & \\
Lai e Peskin (LAI; PESKIN, 2000) & 1,4473 & 0,3299 & \\
Choi et al.(CHOI, 2007) & 1,351 & 0,315 & \\
Presente trabalho & 1,44 & 0,31 & \\
& & & \\
\hline
\end{tabular}

0,63 para os coeficientes de arrasto e sustentação, respectivamente. Esses resultados foram concordantes com os resultados fornecidos no trabalho de Liu, Zheng e Sung (LIU; ZHENG; SUNG, 1998), que catalogaram resultados numéricos onde o $C_{d}$ varia entre 1,17 e 1,58 , e o $C_{l}$ varia entre 0.5 e 0.69 .

As linhas de vorticidade obtidas para o caso em que o cilindro encontra-se estacionário com $R e=200$ é mostrada na figura 4.4. A esteira é composta por vórtices de sinais opostos que se desprendem alternadamente do lado superior e inferior do cilindro.

\subsection{Escoamento em torno do cilindro oscilante}

Nesta seção são apresentados os resultados das simulações em torno do cilindro oscilante. Nas subseções seguintes são apresentados os casos em que o cilindro oscila na mesma direção do escoamento, na direção perpendicular ao escoamento e com oscilação angular. 


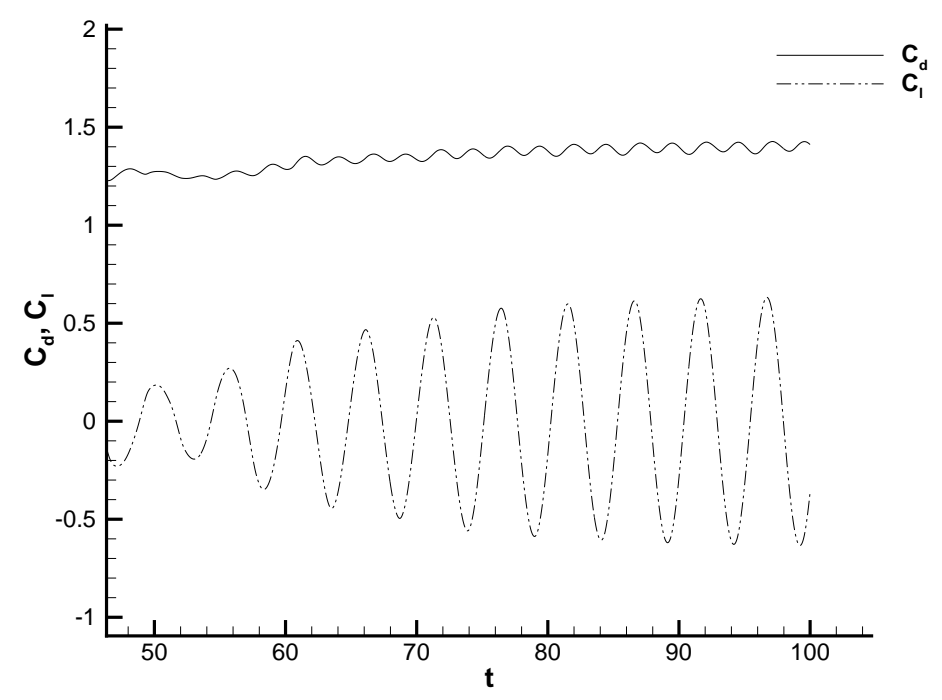

Figura 4.3: Coeficientes de arrasto e sustentação para $R e=200$. Cilindro estacionário

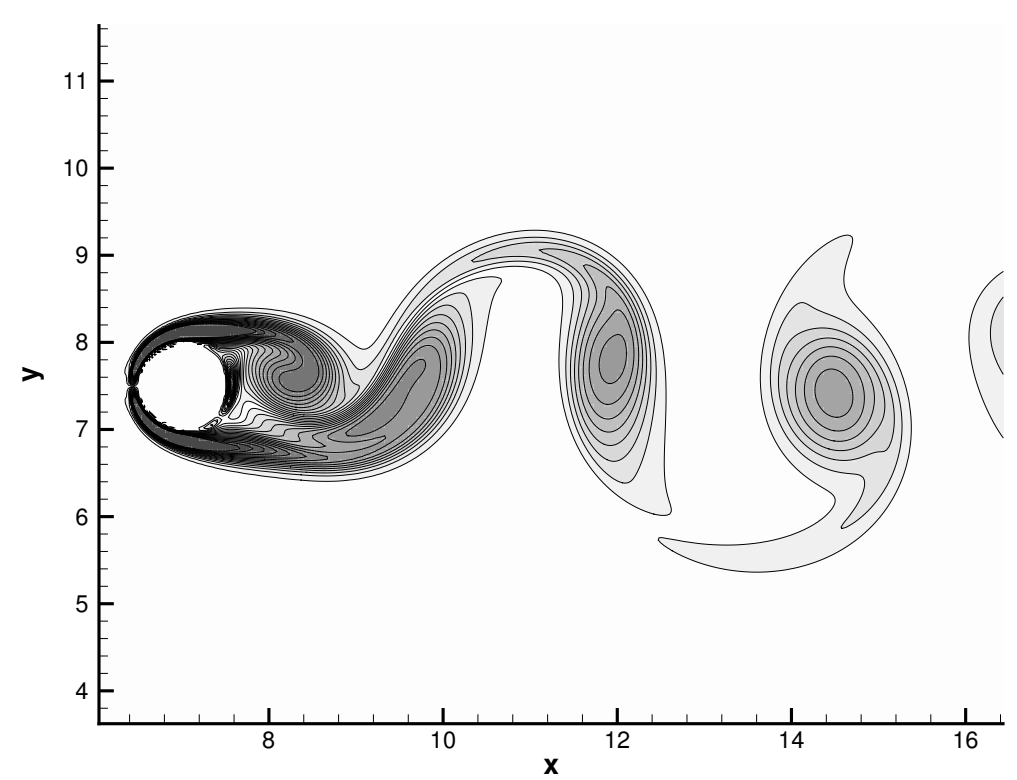

Figura 4.4: Linhas de vorticidade para o cilindro estacionário $-R e=200$.

\subsubsection{Oscilação na mesma direção do escoamento}

A verificação das simulações do escoamento em torno do cilindro oscilando na mesma direção do escoamento foi feita utilizando os resultados fornecidos pelo trabalho de Al-Mdallal, Lawrence e Kocabiyik(M.AL-MDALLAL; LAWRENCE; KOCABIYIK, 2007) para número de Reynolds igual a 200.

A figura 4.5 mostra a curva do coeficiente de sustentação $C_{l}$, quando o cilindro oscila com amplitude $A=0,1$ e frequência $F=0,55$ comparada aos resultados dados em Al- 
Mdallal, Lawrence e Kocabiyik. É possível perceber a similaridade entre as curvas, tanto na amplitude e como no formato da oscilação, apesar da difícil visualização na escala fornecida pelo trabalho encontrado na literatura. O coeficiente de sustentação, devido a baixa frequência de oscilação, apresenta uma oscilação uniforme, sem muitas alterações na curva.
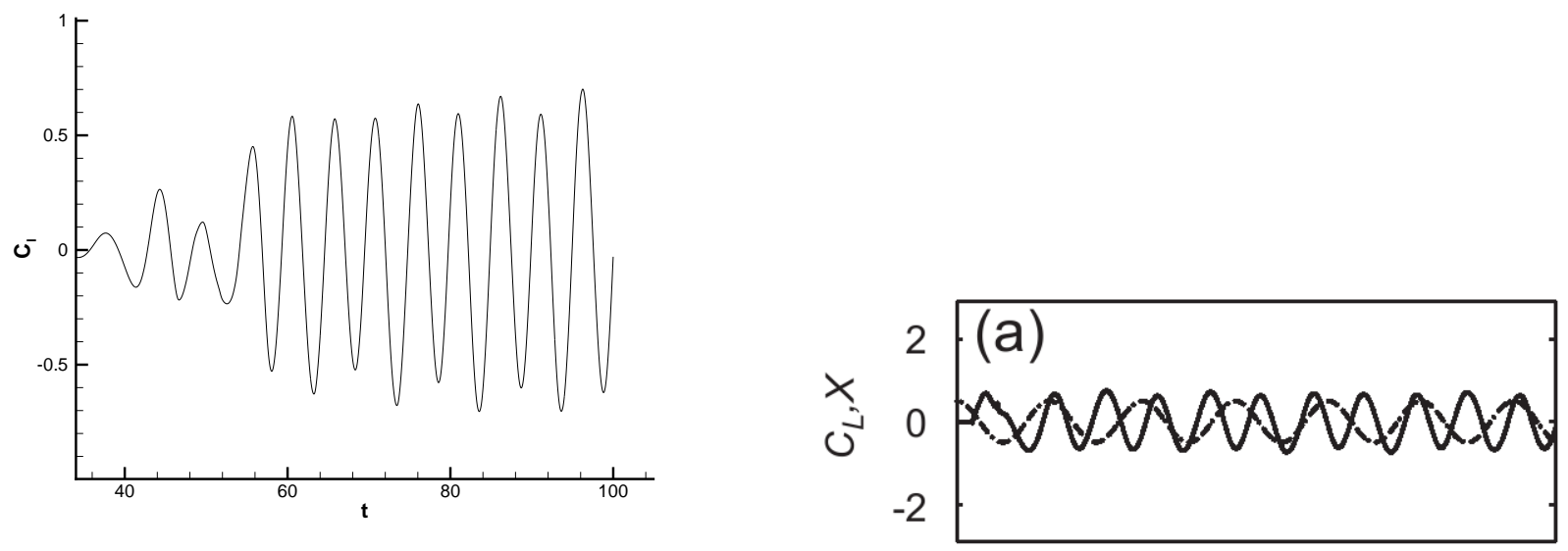

Figura 4.5: Comparação entre os coeficientes de sustentação para o cilindro oscilando na direção $x \operatorname{com} A=0,1, F=0,55$ e $R e=200$. Gráfico à esquerda: presente trabalho. Gráfico à direita: resultados de Al-Mdallal, Lawrence e Kocabiyik(M.AL-MDALLAL; LAWRENCE; KOCABIYIK, 2007)

A figura 4.6 também mostra a comparação entre as curvas do coeficiente de sustentação $C_{l}$ para o caso em que o cilindro oscila com amplitude $A=0,1$ e frequência $F=2,2$. Com o aumento da frequência de oscilação, pode-se perceber a mudança no formato da curva e o surgimento de saliências na mesma. $\mathrm{O}$ valor do $C_{l}$ máximo para o resultado fornecido pelo método das Fronteiras Imersas e pelo trabalho de Al-Mdallal, Lawrence e Kocabiyik(M.AL-MDALLAL; LAWRENCE; KOCABIYIK, 2007) é o mesmo, como pode ser observado.

A comparação entre o coeficiente de sustentação com $A=0,1$ e $F=2,8$ obtido pelo método das Fronteiras Imersas e o coeficiente de sustentação obtido por Al-Mdallal, Lawrence e Kocabiyik(M.AL-MDALLAL; LAWRENCE; KOCABIYIK, 2007) é efetuada na figura 4.7. É possível perceber analogia entre o formato das curvas, no entanto ocorre uma oscilação de amplitude no resultado fornecido pelo presente trabalho. O presente método não teve um bom desempenho para o valor da frequência de oscilação próximo de 3.

Ainda para o caso em que o cilindro oscila na mesma direção do escoamento, foram efetuados dois testes: um para escoamento em torno do cilindro oscilando na mesmo direção do fluido e outro em que o cilindro encontra-se estacionário e ocorre uma variação da velocidade no contorno de entrada. O objetivo dessas simulações foi comparar qualitativamente os dois casos testados. Para ambos os casos, o número de Reynolds utilizado foi $R e=185$, a frequência de oscilação do cilindro foi $\omega=0,9$ e a amplitude de oscilação 

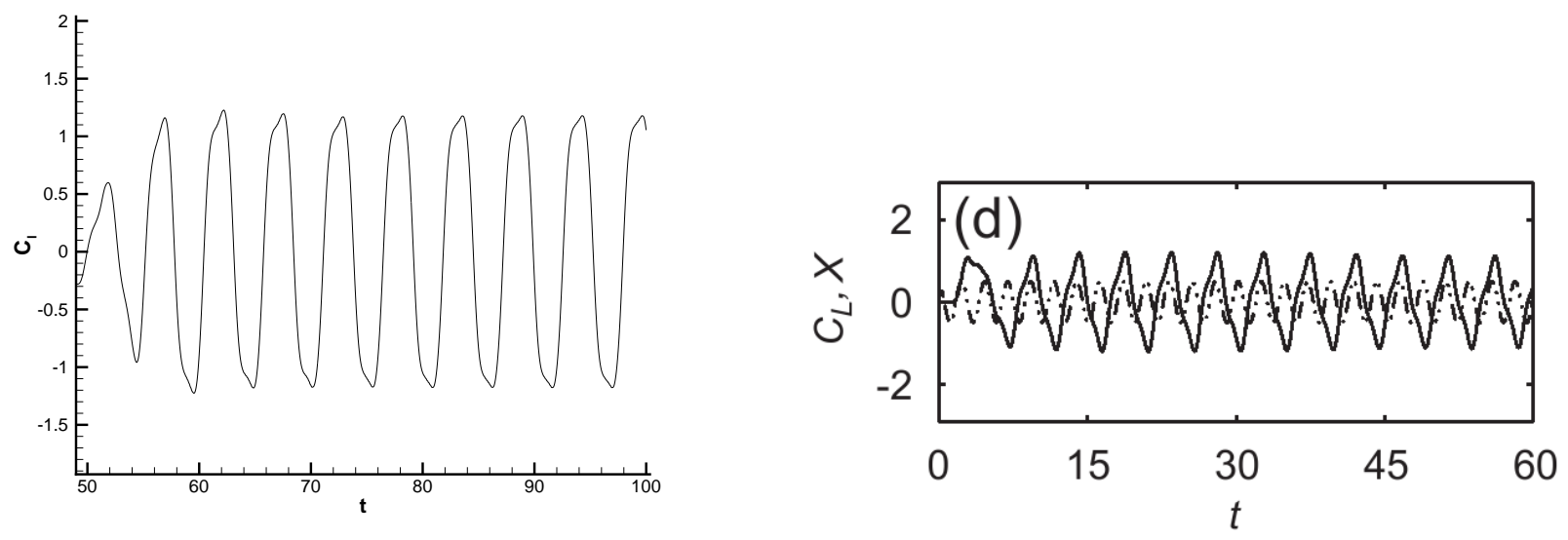

Figura 4.6: Comparação dos coeficientes de sustentação para o cilindro oscilando na direção $x \operatorname{com} A=0,1, F=2,2$ e $R e=200$. Gráfico à esquerda: presente trabalho. Gráfico à direita: resultados de Al-Mdallal, Lawrence e Kocabiyik(M.AL-MDALLAL; LAWRENCE; KOCABIYIK, 2007)
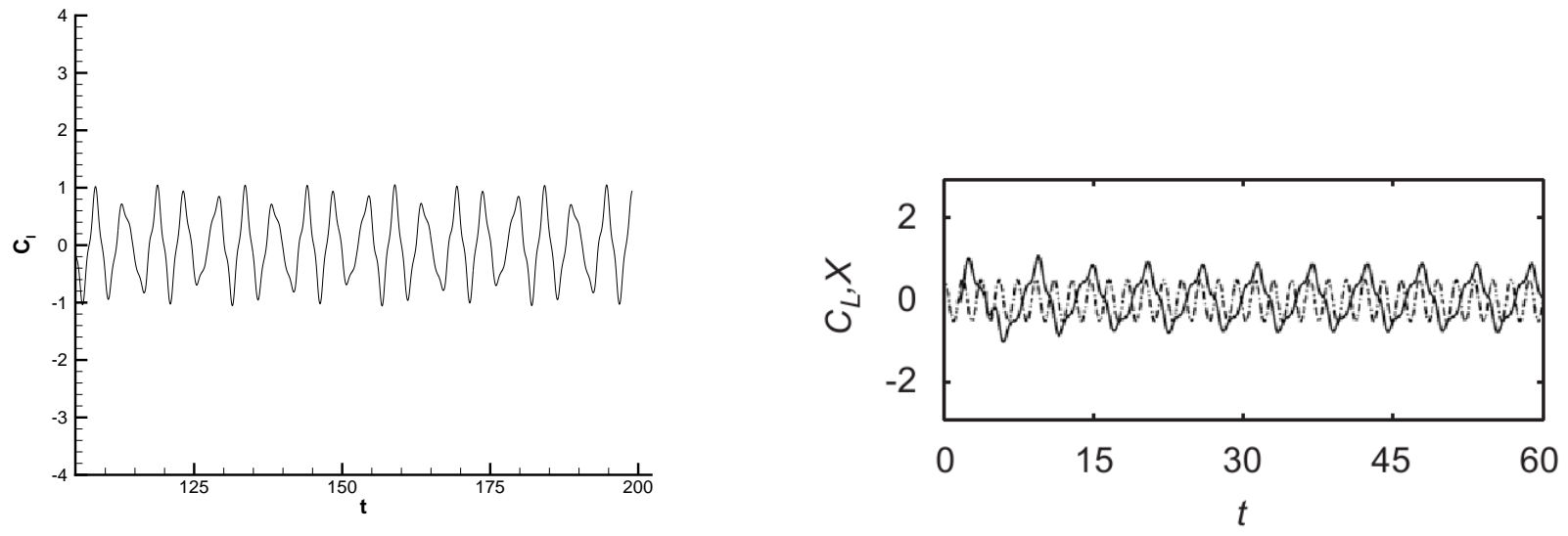

Figura 4.7: Comparação entre os coeficientes de sustentação para o cilindro oscilando na direção $x \operatorname{com} A=0,1, F=2,8$ e $R e=200$. Gráfico à esquerda: presente trabalho. Gráfico à direita: resultados de Al-Mdallal, Lawrence e Kocabiyik(M.AL-MDALLAL; LAWRENCE; KOCABIYIK, 2007)

do cilindro foi tomada igual a $A=0,2$.

A figura 4.8 mostra as linhas de vorticidade obtidas através da simulação em que o cilindro oscila na mesma direção do escoamento e a mostra as linhas de vorticidade para escoamento em torno do cilindro estacionário, mas com variação na velocidade do fluido na entrada do domínio. A analogia entre as esteiras mostram que variar a velocidade do fluido na entrada do domínio computacional tem o mesmo efeito que a oscilação do cilindro.

Os resultados fornecidos pelo método das Fronteiras Imersas também foi validado com os resultados dados por Nobari e Naderan (NOBARI; NADERAN, 2006) para $R e=300$. A figura 4.9 mostra uma comparação entre os contornos de vorticidade quando o cilindro 

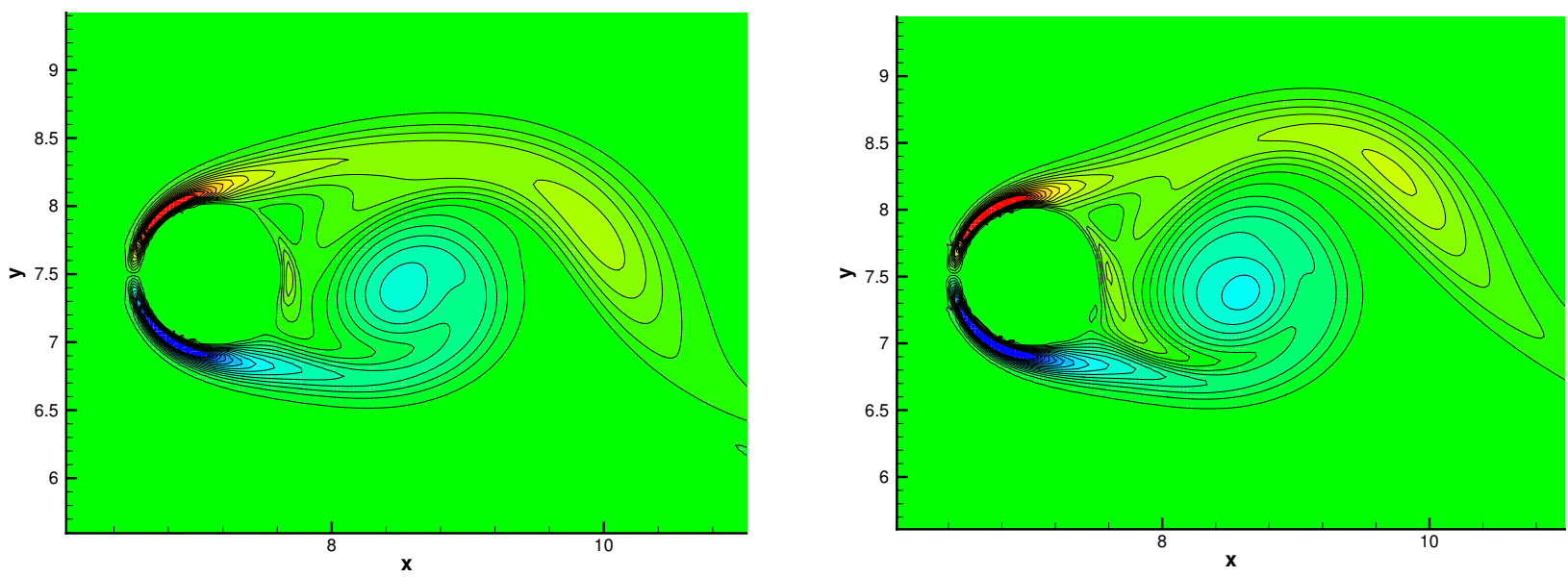

Figura 4.8: Esteira de vórtices pra o cilindro oscilante e estacionário respectivamente.

oscila com amplitude $A=0,05$ e $F=1,4$. As esteiras de vórtices são análogas, ambas com desprendimento de vórtices com sinais opostos e comprimento longitudinal semelhante.
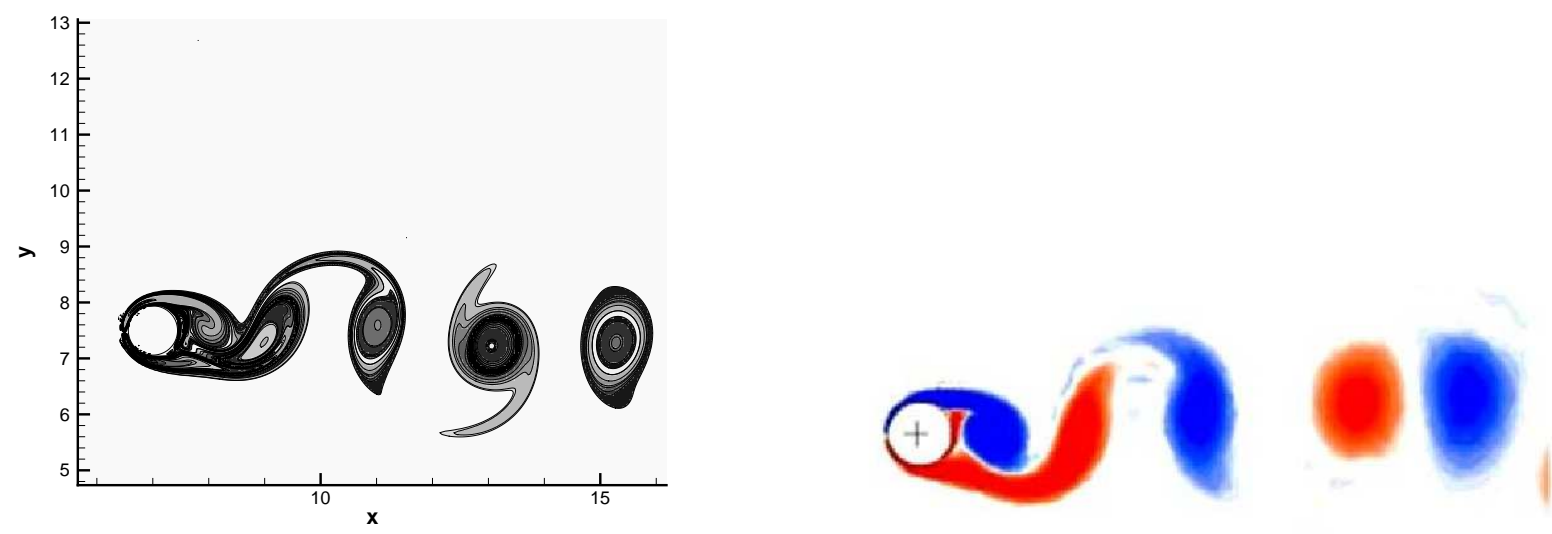

Figura 4.9: Contornos de vorticidade para $\mathrm{Re}=300, \mathrm{~F}=1,4$ e $\mathrm{A}=0,05$. Esquerda: presente trabalho. Direita: Nobari e Naderan (NOBARI; NADERAN, 2006)

A validação para o caso em que o cilindro oscila na mesma direção do escoamento foi feita utilizando os resultados experimentais fornecidos por Griffin e Ramberg (GRIFFIN; RAMBERG, 1976). Quatro valores para o frequência de oscilação do cilindro foram testadas, sendo eles $F=0,5 ; 1,5 ; 2,0$ e 3, 0 . Estas frequências foram escolhidas com o objetivo de capturar o fenômeno da atrelagem síncrona, e a amplitude de oscilação foi tomada igual a $A=0,2$ para todos os casos. O número de Reynolds utilizado foi, para todos os casos, $R e=190$.

Simulando o escoamento em torno do cilindro oscilando com frequências $F=$ 0,$5 ; 1,5 ; 2,0$ e 3,0 , são observados quatro tipos diferentes de esteiras de vórtices. As figuras 4.10,4.11, 4.12 e 4.13 mostram o desprendimento de vórtices para estes casos. O cilindro encontra-se na mesma posição $x$ em todas elas. 
O desprendimento de vórtices para o caso em que o cilindro oscila com frequência $F=0,5$ mostrado na figura 4.10 apresenta apresenta muitas similaridades com o caso do cilindro estacionário, com uma mudança de fase de 180 graus. No entanto, com o aumento da frequência de oscilação, ocorre um aumento no espaçamento longitudinal na esteira de vórtices. Este aumento pode ser melhor observado na figura 4.11, que mostra a esteira de vórtices formada para o caso em que o cilindro oscila com frequência $F=1,5$.

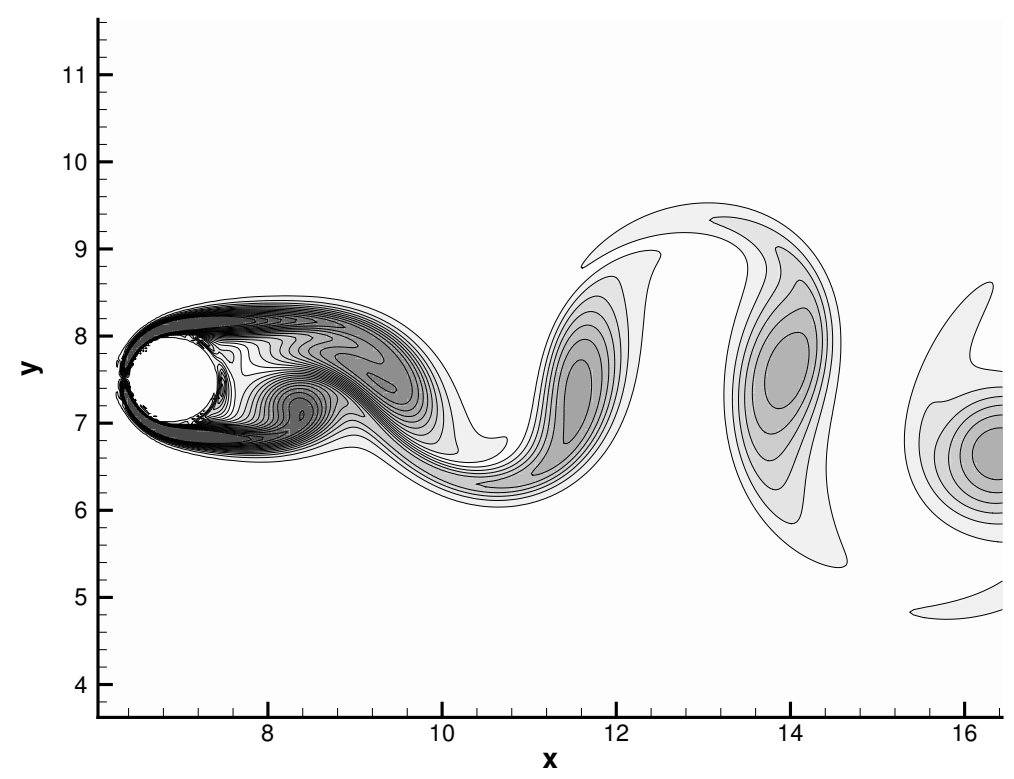

Figura 4.10: Linhas de vorticidade para o cilindro oscilando na direção $x$ com frequência $F=0,5$ e $R e=190$.

Para o cilindro oscilando com frequência $F=2,0$ é observada uma esteira com o desprendimento de dois vórtices acoplados, como pode ser observado na figura 4.12.

Para o caso em que o cilindro oscila com frequência $F=3,0$ ocorre a formação de uma esteira de vórtices mais complexa, como mostra a figura 4.13. A jusante do cilindro ocorre a formação de dois vórtices de sinais opostos. Dos lados superior e inferior do cilindro, estes vórtices fundem-se com o próximo vórtice, desprendendo assim vórtices com escalas maiores.

De acordo com Griffin e Ramberg (GRIFFIN; RAMBERG, 1976), a atrelagem síncrona ocorre para valores de frequências entre $120 \%$ e $250 \%$ aproximadamente, o que é concordante com os resultados fornecidos pelo Método das Fronteiras Imersas. Foi possível capturar este fenômeno para os valores de frequência $F=1,5$ e $F=2,0$. Para frequências iguais a $F=0,5$ e $F=3,0$ o fenômeno não ocorre e a esteira é formada por cinco vórtices. Na figura (4.12), é considerada a formação de cinco vórtices ao invés de oito devido a coalescência de de vórtices de mesmo sinal.

Pode-se perceber que o método das Fronteiras Imersas forneceu bons resultados para a simulação do escoamento em torno de um cilindro que oscila na mesma direção do fluido. 


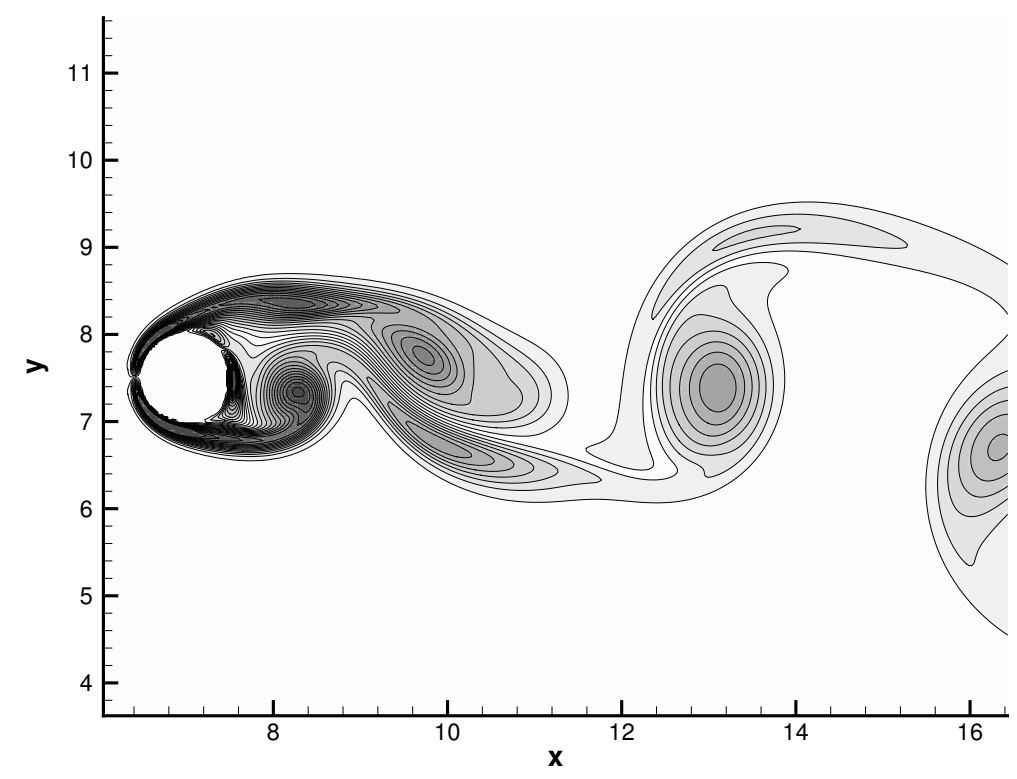

Figura 4.11: Linhas de vorticidade para o cilindro oscilando na direção $x$ com frequência $F=1,5$ e $R e=190$.

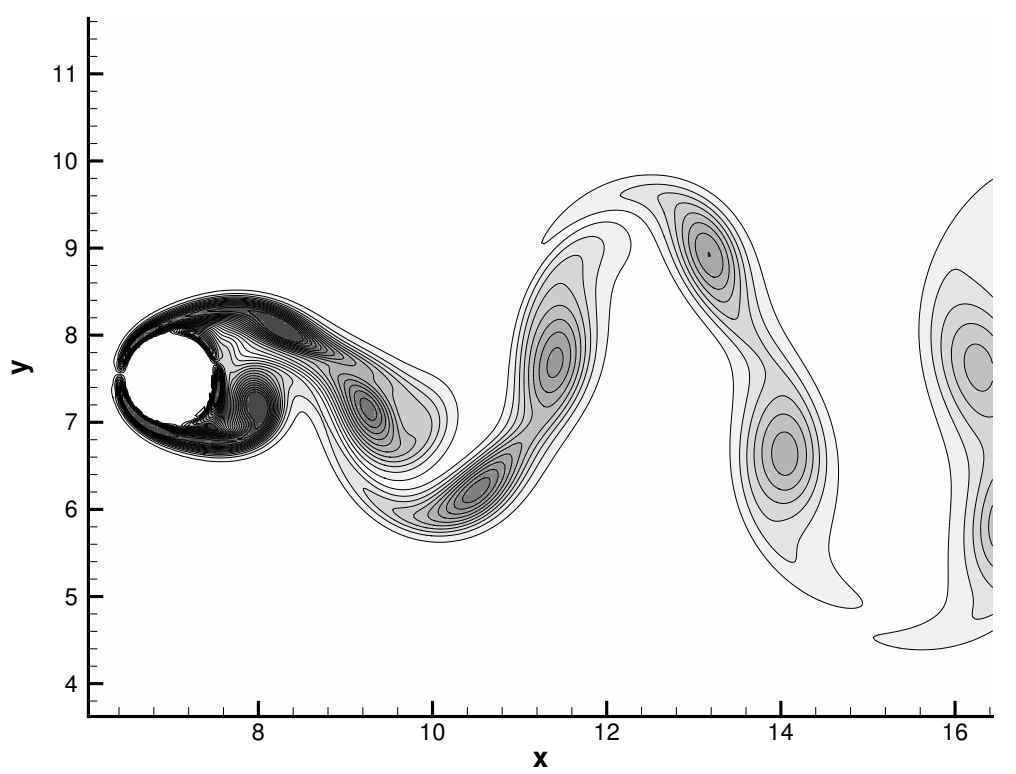

Figura 4.12: Linhas de vorticidade para o cilindro oscilando na direção $x$ com frequência $F=2,0$ e $R e=190$.

\subsubsection{Oscilação na direção perpendicular ao escoamento}

Para verificar os resultados das simulações do escoamento em torno do cilindro oscilando na direção transversal ao escoamento foi utilizado o trabalho de Nobari e Naderan (NOBARI; NADERAN, 2006). Foram testados os casos em que a frequência de oscilação assume valores de $F=0,6$ e $F=1,05$ e a amplitude de oscilação do cilindro foi $A=0,2$ e 


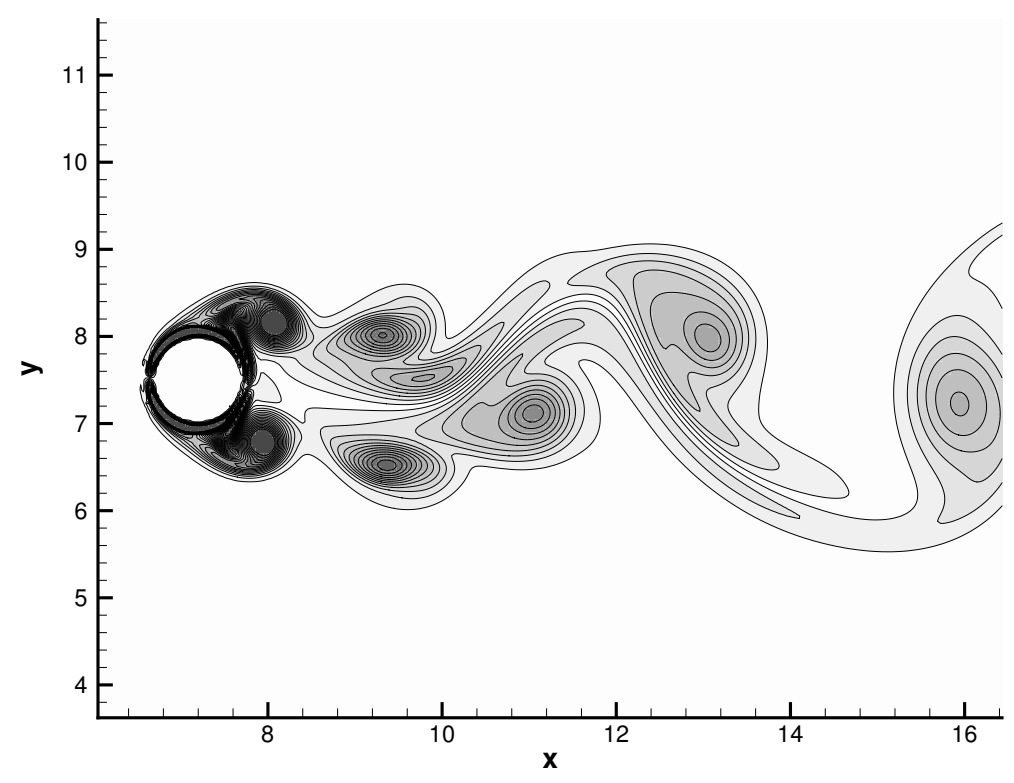

Figura 4.13: Linhas de vorticidade para o cilindro oscilando na direção $x$ com frequência $F=3,0$ e $R e=190$.

$A=0,4$ e o número de Reynolds adotado foi $R e=100$.

A figura 4.14 mostra as curvas do coeficiente de arrasto e sustentação para o caso em que o cilindro oscila com amplitude $A=0,2$ e frequência $F=0,6$. Para estes valores, o fenômeno da atrelagem síncrona não ocorre, o que é concordante com os resultados dados por Nobari e Naderan (NOBARI; NADERAN, 2006). De acordo com o trabalho de Nobari e Naderan, quando o fenômeno da atrelagem síncrona não ocorre, o desprendimento de vórtices na esteira é intermitente, o que caracteriza a presença de duas frequências diferentes. A intermitência no desprendimento de vórtices no caso em que $A=0,2$ e $F=0,6$ é mostrada na figura 4.15 .

Os coeficientes de arrasto e sustentação obtidos no caso em que $A=0,2$ e $F=1,05$ são ilustrados na figura 4.16 e a esteira de vórtices é mostrada na figura 4.17. Para estes valores, o fenômeno da atrelagem síncrona é observado, o que caracterizado pela formação de uma esteira regular, resultado da sincronia entre a frequência de oscilação do cilindro e a frequência de desprendimento.

Para amplitude de oscilação $A=0,4$ e $F=0,6$, o fenômeno da atrelagem síncrona não ocorre. Os coeficiente de arrasto e sustentação para este caso são mostrados da figura 4.18 e os contornos de vorticidade são apresentados na figura 4.19, onde também é possível perceber o desprendimento intermitente de vórtices na esteira.

A figura 4.20 ilustra os resultados obtidos para $C_{l}$ e $C_{d}$ para a simulação em que $A=0,4$ e $F=1,05$. A respectiva esteira de vórtices é mostrada na figura 4.21. Para estes valores, o fenômeno da atrelagem síncrona é observado, e novamente há formação de uma esteira de vórtices com desprendimento regular. 


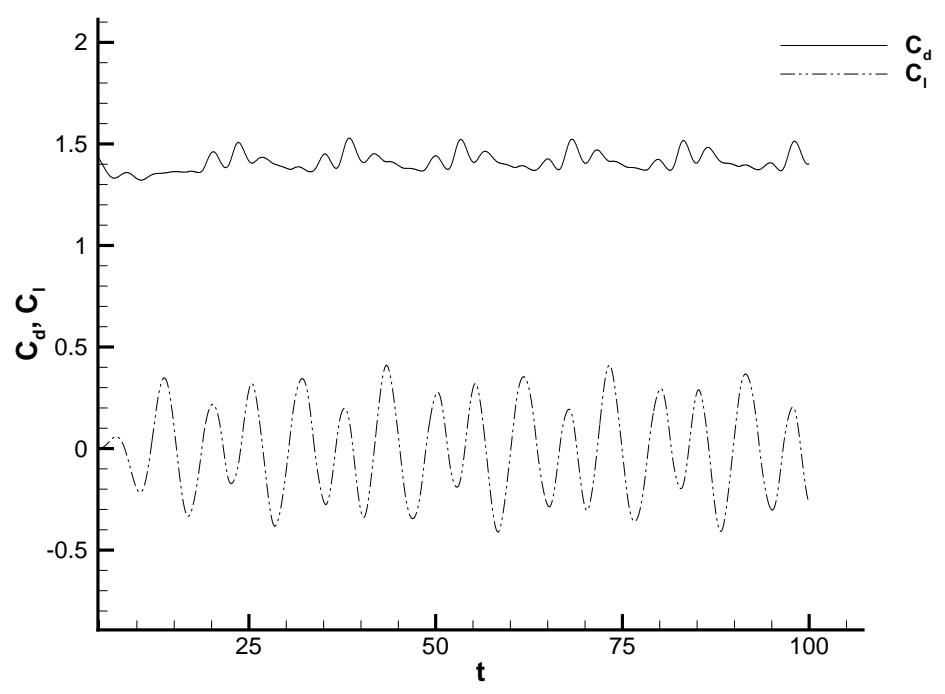

Figura 4.14: $C_{d}$ e $C_{l}$ para o cilindro oscilando na direção $y \operatorname{com} A=0,2, F=0,6$, $R e=100$.

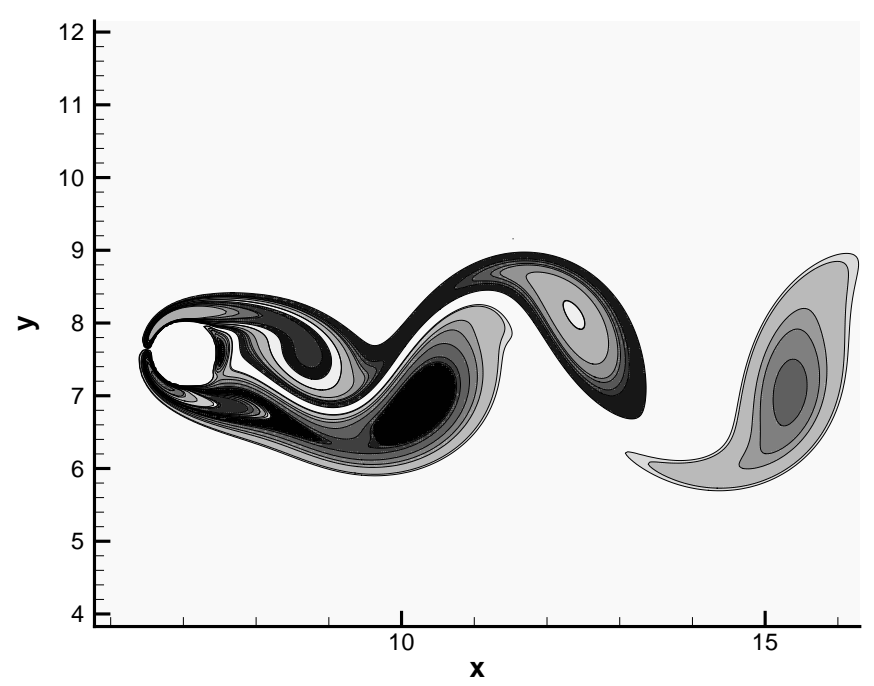

Figura 4.15: Linhas de vorticidade para o cilindro oscilando na direção $y \operatorname{com} A=0,2$, $F=0,6$ e $R e=100$.

A tabela 4.2 compara os valores máximos obtidos para o coeficiente de sustentação $C_{l}$ para o caso em que o cilindro oscila com amplitude $A=0,2$ com dois valores para a frequência: $F=0,6$ e $F=1,05$. O resultados obtidos utilizando o método das fronteiras imersas apresenta resultados concordantes com os obtidos por Nobari e Naderan (NOBARI; NADERAN, 2006). Pode-se perceber um aumento no coeficiente de sustentação para o caso em que $F=1,05$, ou seja, quando o fenômeno da atrelagem síncrona ocorre. 


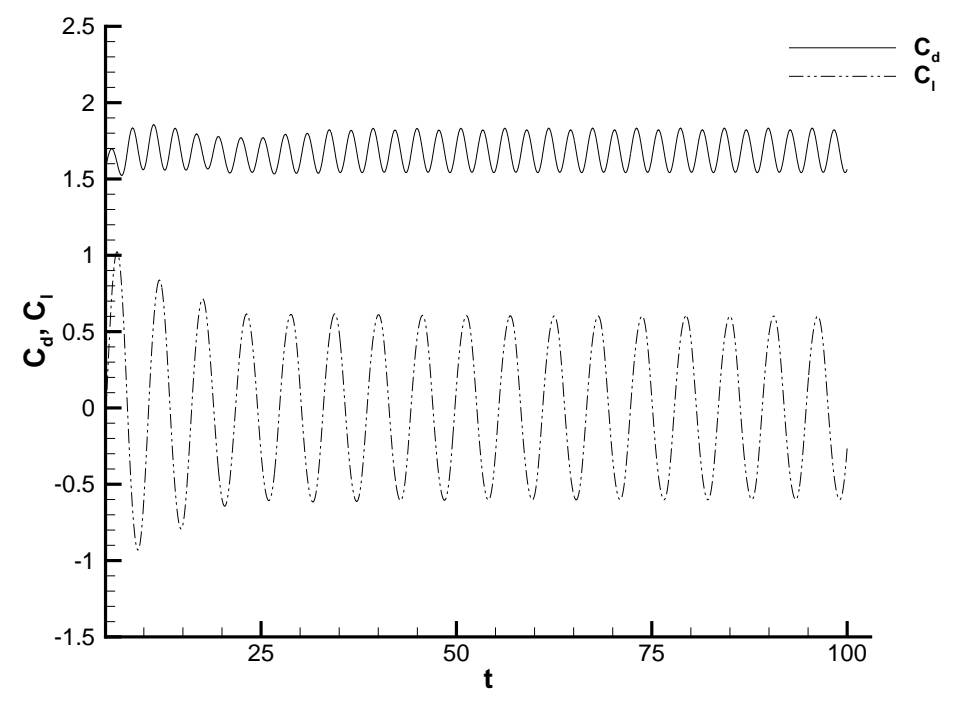

Figura 4.16: $C_{d}$ e $C_{l}$ para o cilindro oscilando na direção y com $A=0,2, F=1,05$, $R e=100$.

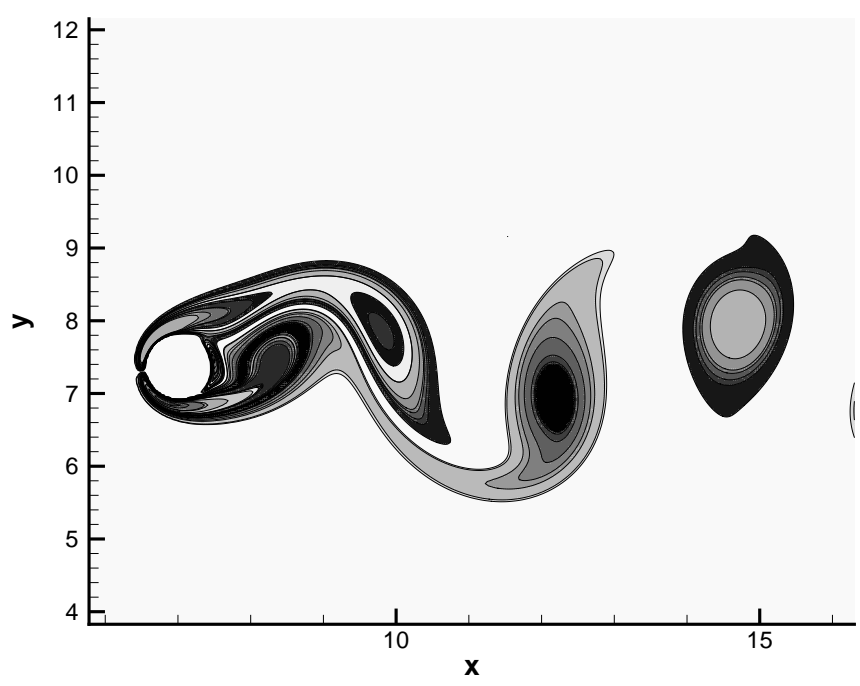

Figura 4.17: Linhas de vorticidade para o cilindro oscilando na direção y com $A=0,2$, $F=1,05$ e $R e=100$.

O coeficiente de arrasto $C_{d}$ máximo para o caso em que o cilindro oscila com amplitude $A=0,4$ e frequência $F=1,05$ obtido através do método de Fronteiras Imersas foi $C_{d}=$ 2,309, concordante com o resultado obtido por Nobari e Naderan (NOBARI; NADERAN, 2006), que foi $C_{d}=2,31$.

Através da verificação efetuada aqui, pode-se concluir que o Método das Fronteiras Imersas tem um bom desempenho na simulação do caso em que o cilindro oscila na direção 


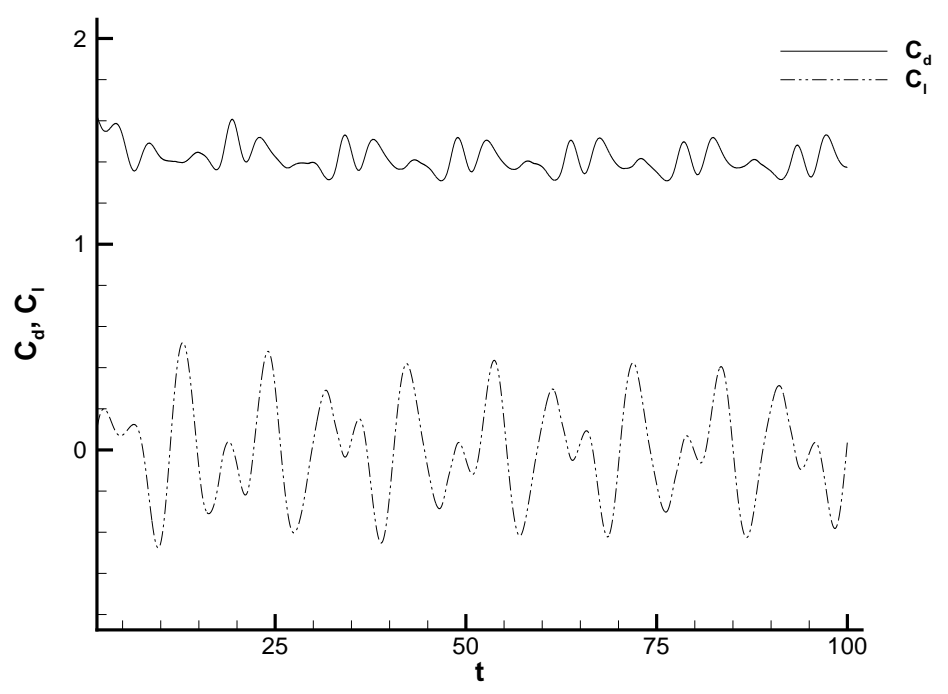

Figura 4.18: $C_{d}$ e $C_{l}$ para o cilindro oscilando na direção $y \operatorname{com} A=0,4, F=0,6$, $R e=100$.

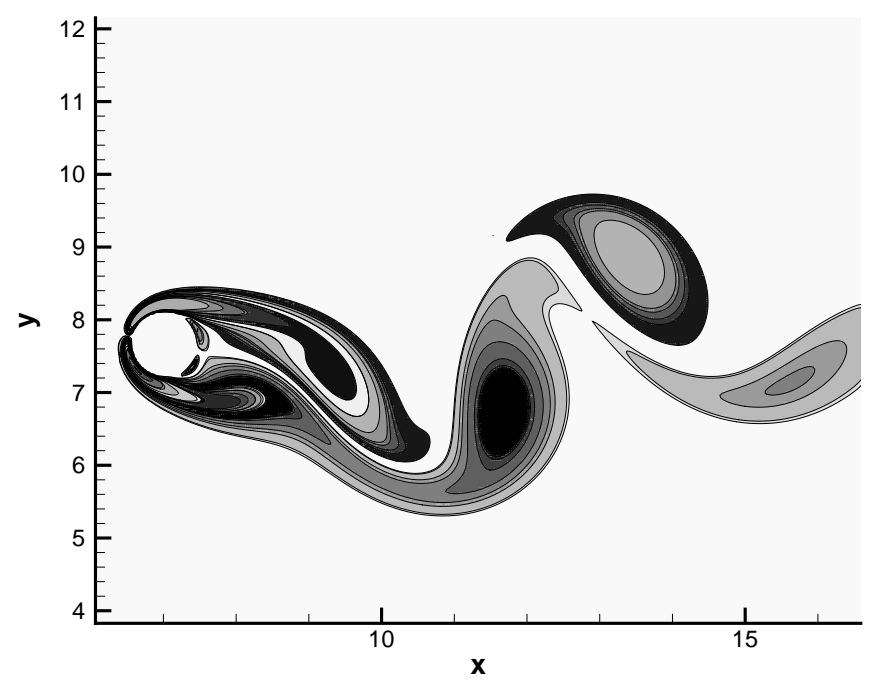

Figura 4.19: Linhas de vorticidade para o cilindro oscilando na direção y com $A=0,4$, $F=0,6$ e $R e=100$.

perpendicular ao escoamento.

\subsubsection{Oscilação Angular}

Para o caso em que o cilindro que serve de obstáculo ao escoamento efetua um movimento oscilatório de rotação em torno do próprio eixo, os resultados foram verificados utilizando 


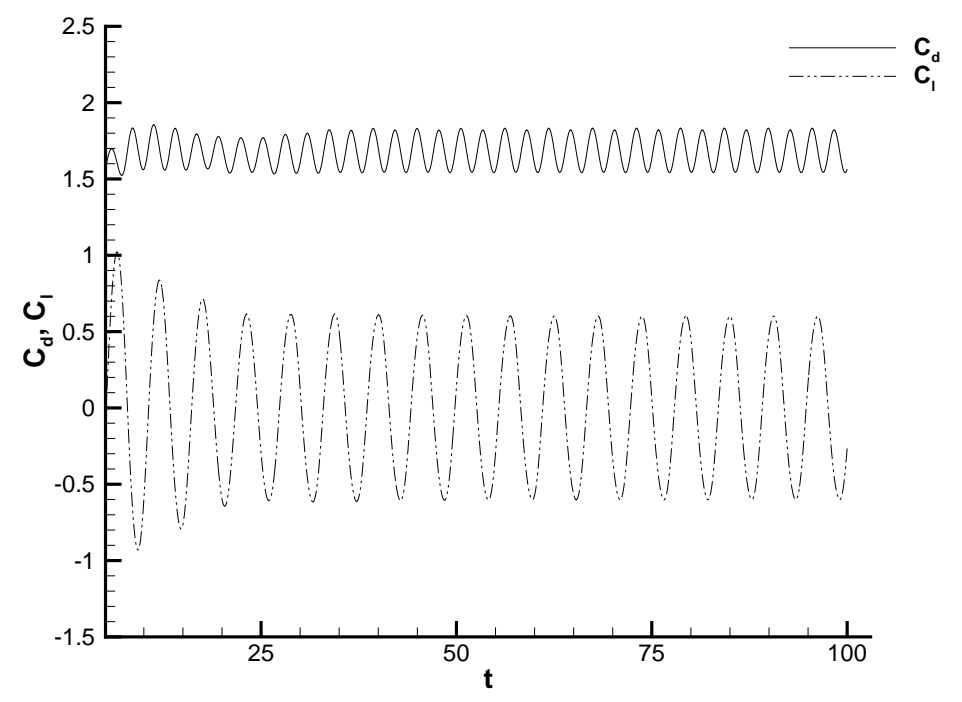

Figura 4.20: $C_{d}$ e $C_{l}$ para o cilindro oscilando na direção y com $A=0,4, F=1,05$, $R e=100$.

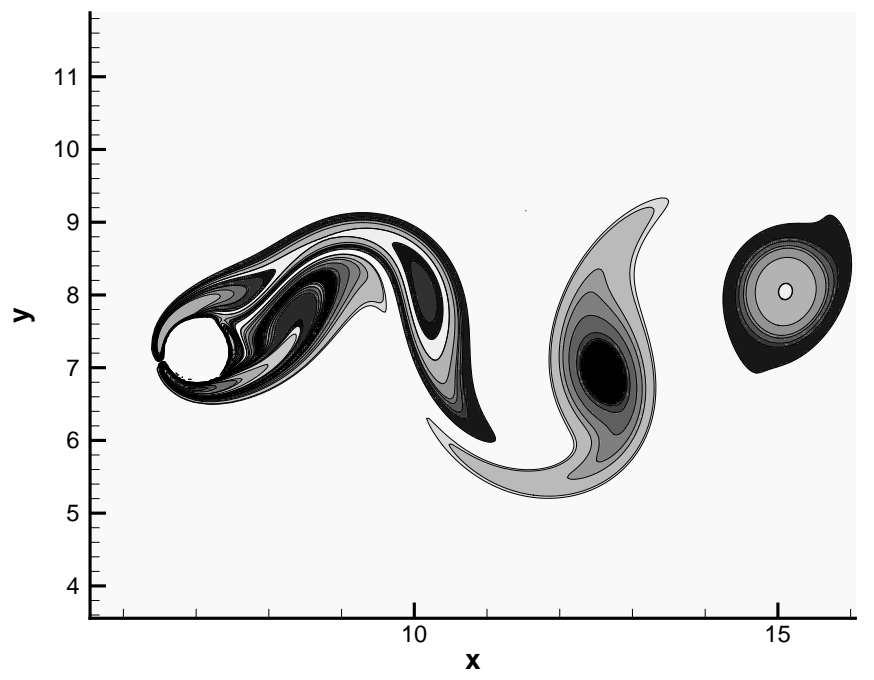

Figura 4.21: Linhas de vorticidade para o cilindro oscilando na direção y com $A=0,4$, $F=1,05$ e $R e=100$.

os resultados numéricos dados por Baek e Sung (BAEK; SUNG, 1998).

A primeira simulação foi feita para o caso em que o cilindro rotaciona com um ângulo de $15^{\circ}$ e duas frequências de oscilação foram testadas: $f=0.15$ e $F=0.17$. A figura 4.22 apresenta a curva do coeficiente de sustentação $C_{l}$ máximo para o caso em que o cilindro rotaciona com ângulo de $15^{\circ}$ e frequência de oscilação $F=0.15$. De acordo com (BAEK; SUNG, 1998), a frequência de oscilação $F=0.15$ é um ponto crítico onde ocorre 
Tabela 4.2: Comparação $C_{l}$ para o caso em que o cilindro oscila com $A=0,2$.

\begin{tabular}{|c|c|c|}
\hline & $F=0,6$ & $F=1,05$ \\
\hline Nobari e Naderan (NOBARI; NADERAN, 2006) & 0,5 & 0,6 \\
\hline Presente trabalho & 0,4 & 0,6 \\
\hline
\end{tabular}

o fenômeno de atrelagem síncrona. A diminuição de amplitude no início e no final do período da oscilação mostra a ocorrência do fenômeno.

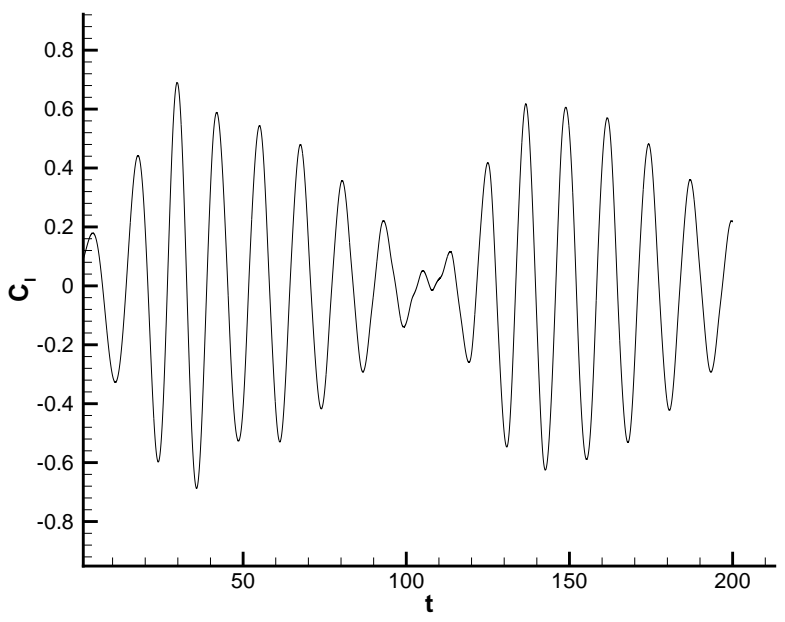

Figura 4.22: Coeficiente de sustentação para o cilindro rotativo com ângulo máximo de rotação de $15^{\circ}$ e frequência de oscilação $F=0.15$.

A figura 4.23 mostra a curva do coeficiente de sustentação $C_{l}$ para o caso em que o cilindro rotaciona com ângulo máximo de rotação de $15^{\circ}$ e frequência de oscilação $F=0.17$. Através da análise da curva é possível perceber que para este valor de frequência de oscilação, o fenômeno da atrelagem síncrona não ocorre, como já era esperado.

A tabela 4.3 apresenta uma comparação entre os valores para $C_{l}$ fornecidos pelo trabalho de (BAEK; SUNG, 1998) e os resultados obtidos com o presente método.

O segundo teste foi efetuado para o caso em que o cilindro encontra-se oscilando com um ângulo máximo de rotação igual a $30^{\circ}$

A figura 4.24 mostra o resultado obtido utilizando o método de Fronteiras Imersas para o caso em que o cilindro rotaciona com ângulo $30^{\circ}$ e oscila com frequência $F=0.14$. Por ser uma frequência crítica do intervalo de frequência testado por (BAEK; SUNG, 1998), a curva apresenta a ocorrência de atrelagem síncrona, como pode ser observado.

A curva para o coeficiente de arrasto e sustentação quando o cilindro oscila com ângulo 


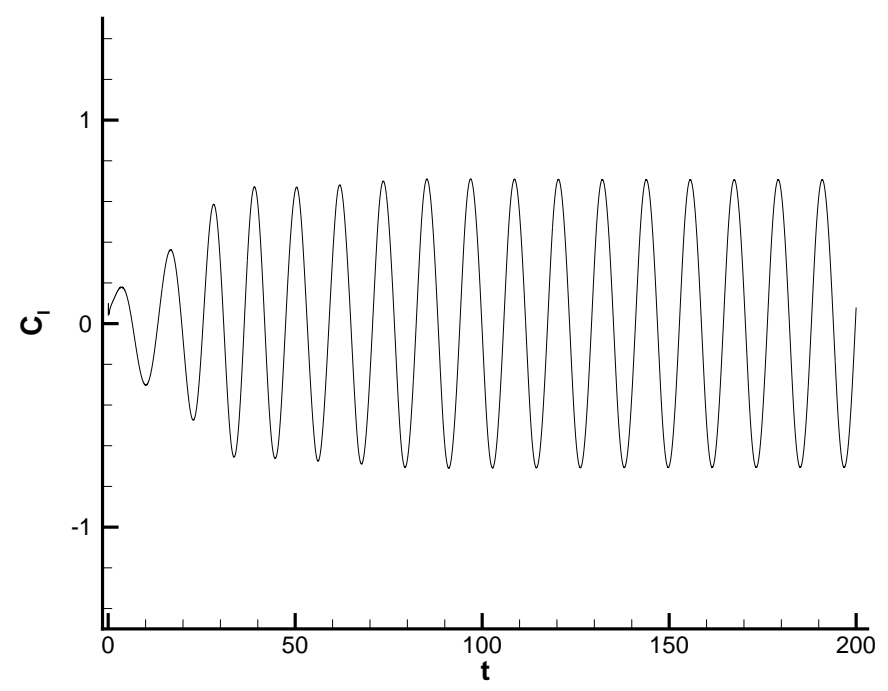

Figura 4.23: Coeficiente de sustentação para o cilindro rotativo com ângulo de $15^{\circ} \mathrm{e}$ frequência de oscilação $F=0.17$.

Tabela 4.3: Comparação do $C_{l}$ máximo para para o cilindro rotacionando com ângulo máximo de $15^{\circ}$.

\begin{tabular}{l|c|c|c}
\hline \hline & $F=0.15$ & $F=0.17$ & \\
\hline \hline & & & \\
Baek e Sung (BAEK; SUNG, 1998) & 0.5 & 0.75 & \\
Presente trabalho & 0.6 & 0.7 & \\
& & & \\
\hline
\end{tabular}

máximo de rotação igual a $30^{\circ}$ com frequência $f=17$ é mostrada na figura 4.25 . O fenômeno da atrelagem síncrona não ocorre, para essa frequência de oscilação, o que resulta numa curva de amplitude constante.

A tabela 4.4 mostra os resultados para o coeficiente de sustentação para o caso em que o cilindro oscila com ângulo máximo de $30^{\circ}$ comparados aos resultados dados por Baek e Sung (BAEK; SUNG, 1998).

No caso em que o cilindro rotaciona com um ângulo máximo de rotação igual a $60^{\circ}$, três valores de frequência de oscilação foram testados: $F=0.14, F=0.17$ e $F=0.20$.

A figura 4.27 e a figura 4.28 mostram as curvas para o coeficiente de sustentação para o caso em que o cilindro oscila com ângulo máximo de $60^{\circ}$ com frequências $F=0,14$ e $F=0,17$, respectivamente.

A curva para o coeficiente de sustentação no caso em que o cilindro rotaciona com ângulo máximo de $60^{\circ}$ e com frequência $F=0,20$ é mostrada na figura 4.29.

A tabela 4.5 mostra os valores máximos obtidos para o coeficiente de sustentação para 


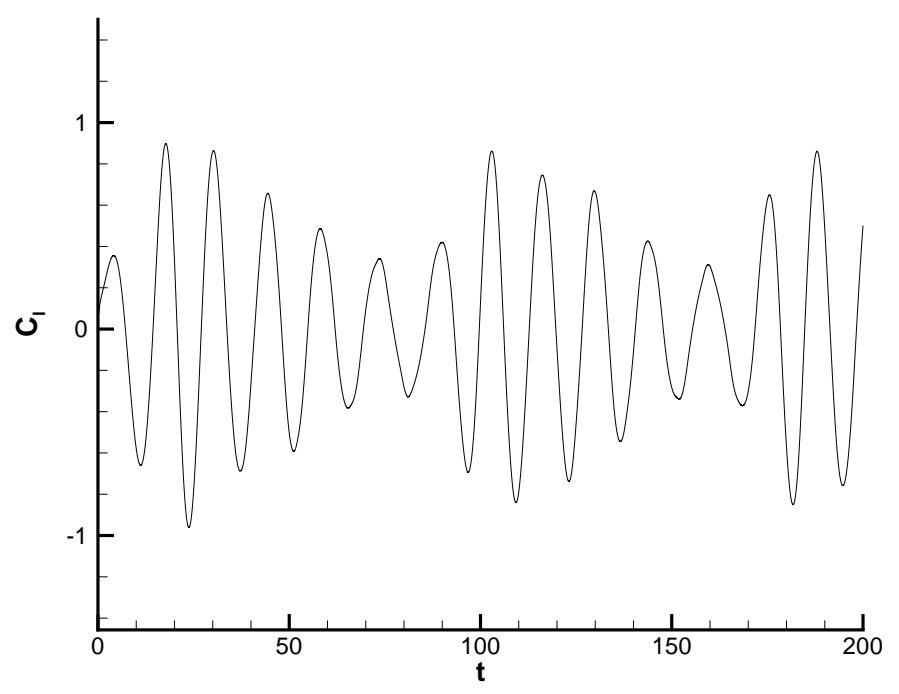

Figura 4.24: Coeficiente de sustentação para o cilindro rotativo com ângulo de $30^{\circ}$ e frequência de oscilação $F=0.14$.

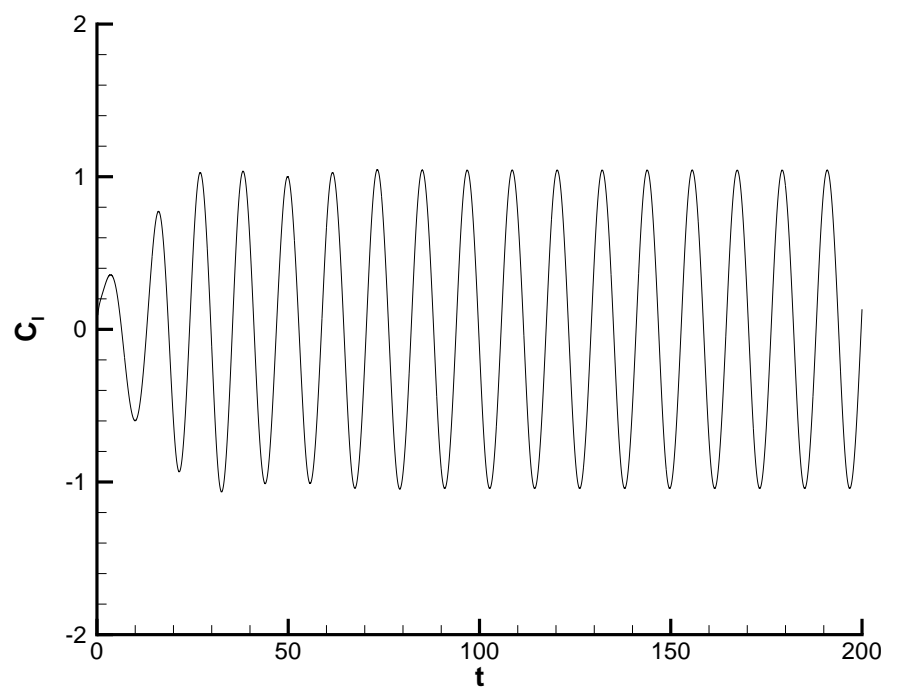

Figura 4.25: Coeficiente de sustentação para o cilindro rotativo com ângulo de $30^{\circ}$ e frequência de oscilação $F=0.17$.

o caso em que o cilindro rotaciona com ângulo máximo de $60^{\circ}$ comparados aos resultados dados por Baek e Sung (BAEK; SUNG, 1998).

A verificação dos resultados feitas utilizando os resultados fornecidos por Baek e Sung (BAEK; SUNG, 1998) mostra que o Método das Fronteiras Imersas é apto para simular o escoamento em torno de um cilindro rotativo para baixos números de Reynolds. 


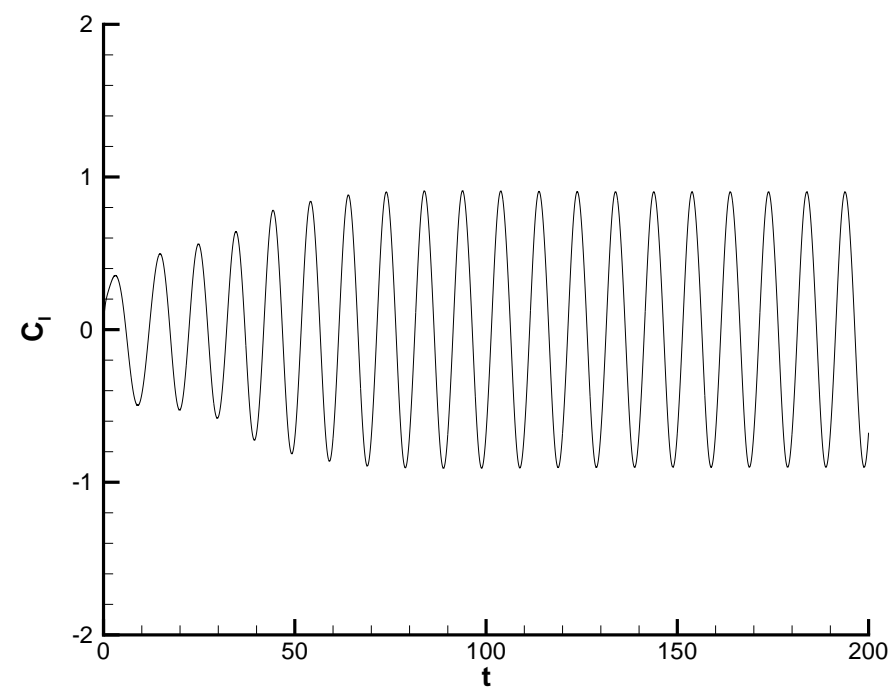

Figura 4.26: Coeficiente de sustentação para o cilindro rotativo com ângulo de $30^{\circ} \mathrm{e}$ frequência de oscilação $F=0.20$.

Tabela 4.4: Comparação do $C_{l}$ máximo para cilindro rotacionando com ângulo máximo de $30^{\circ}$.

\begin{tabular}{l|c|c|c|}
\hline \hline & $F=0,14$ & $F=0,17$ & $F=0,20$ \\
\hline \hline & & & \\
Baek e Sung (BAEK; SUNG, 1998) & 0,75 & 1,1 & 0,48 \\
Presente trabalho & 0,86 & 1,04 & 0,9 \\
& & & \\
\hline
\end{tabular}

Tabela 4.5: Comparação do $C_{l}$ máximo para cilindro rotacionando com ângulo máximo de $60^{\circ}$.

\begin{tabular}{l|c|c|c|}
\hline \hline & $F=0,14$ & $F=0,17$ & $F=0,20$ \\
\hline \hline & & & \\
Baek e Sung (BAEK; SUNG, 1998) & 1,4 & 1,6 & 0,81 \\
Presente trabalho & 1,1 & 1,63 & 1,40 \\
& & & \\
\hline
\end{tabular}

\subsection{Considerações finais}

Neste capítulo, os resultados fornecidos pelo Método das Fronteiras Imersas foram verificados e validados quando comparados a resultados numéricos e experimentais encontrados na literatura. As simulações foram efetuadas para quatro diferentes casos, escoamento em 


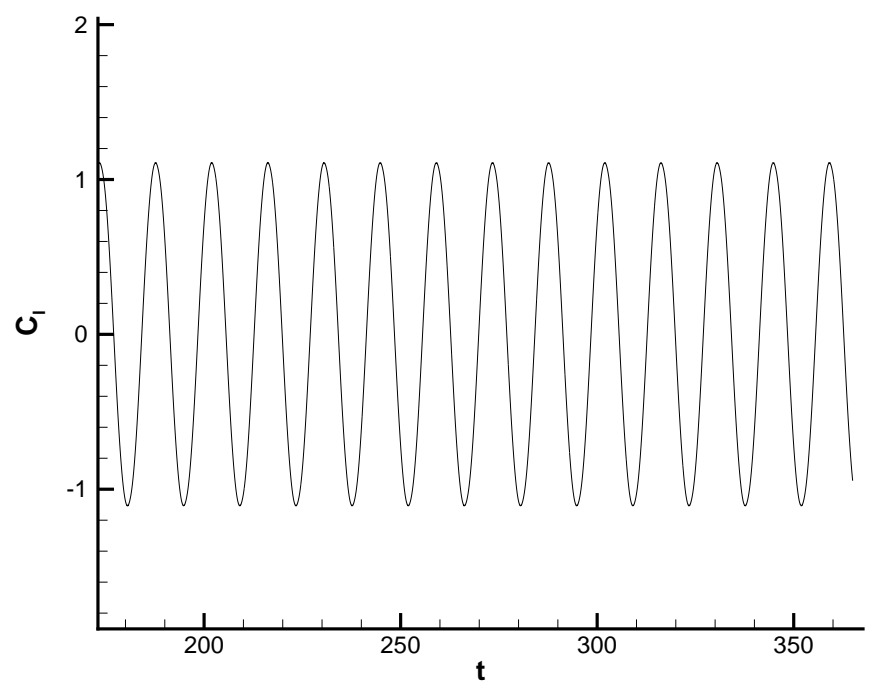

Figura 4.27: Coeficiente de sustentação para o cilindro rotativo com ângulo de $60^{\circ}$ e frequência de oscilação $F=0.14$.

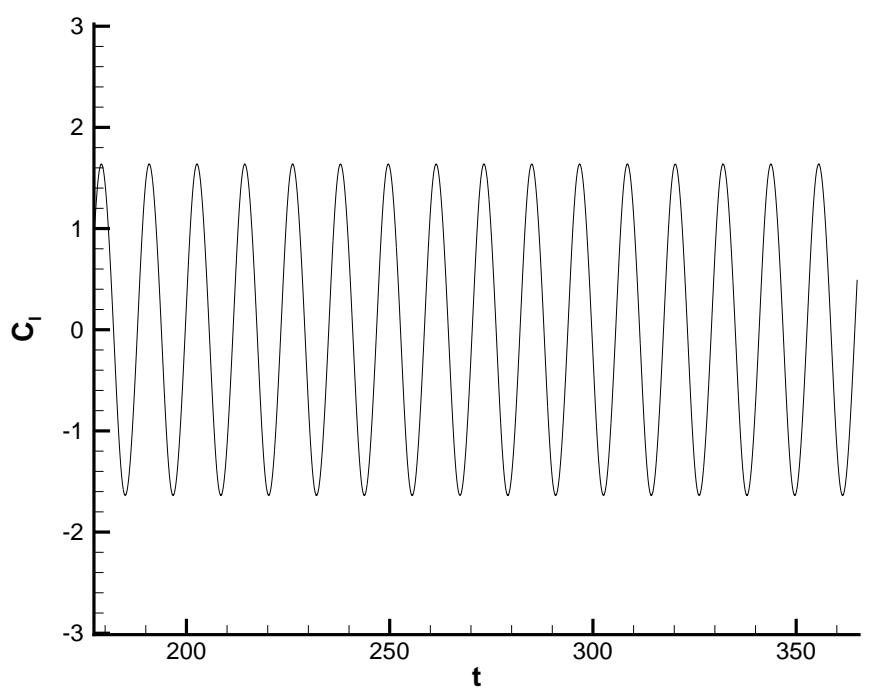

Figura 4.28: Coeficiente de sustentação para o cilindro rotativo com ângulo de $60^{\circ}$ e frequência de oscilação $F=0.17$.

torno: do cilindro estacionário, do cilindro oscilando na mesma direção do escoamento, cilindro oscilando na direção perpendicular ao escoamento, e cilindro rotativo. Foi possível capturar e analisar o Fenômeno da Atrelagem Síncrona e pode-se concluir que o presente método, teve um bom desempenho. 


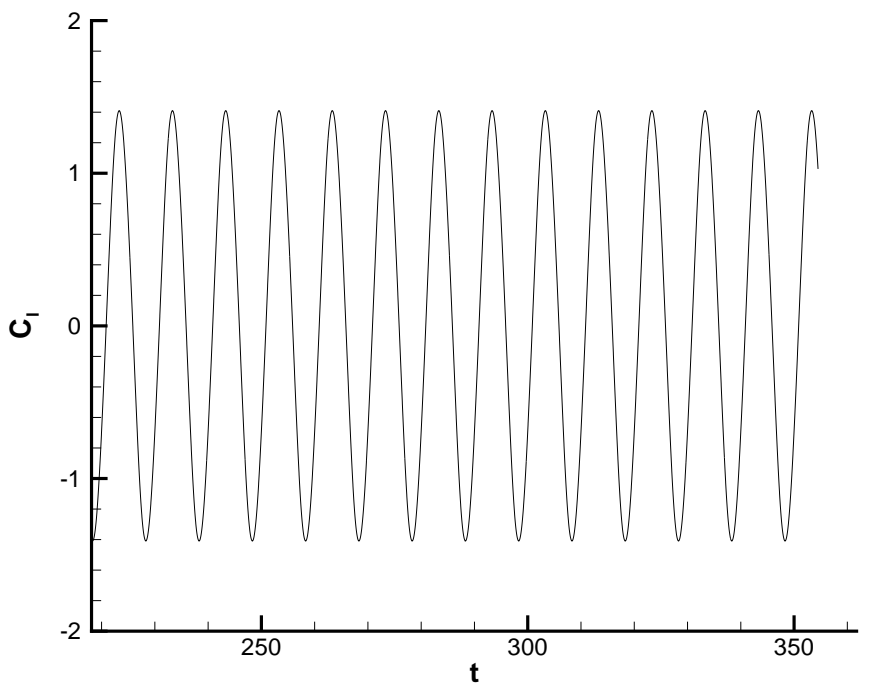

Figura 4.29: Coeficiente de sustentação para o cilindro rotativo com ângulo de $60^{\circ} \mathrm{e}$ frequência de oscilação $F=0.20$. 


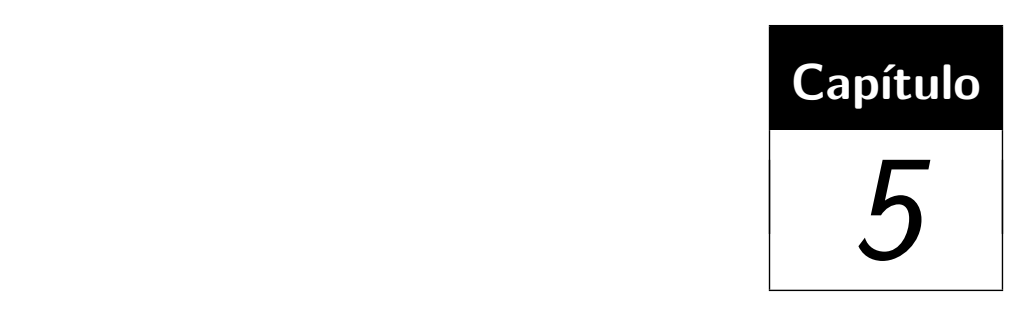

\section{Conclusões}

O estudo do escoamento em torno de obstáculos foi alvo da atenção dos pesquisadores em Mecânica dos Fluidos Computacional devido a sua grande aplicabilidade em diversas áreas da engenharia, como o escoamento em torno de tubos de perfuração de poços de petróleo, por exemplo. Para simular computacionalmente esse tipo de problema, é necessária uma atenção especial ao tipo de malha a ser utilizada, de acordo com o formato do corpo que serve como obstáculo ao escoamento. Muitas vezes, torna-se necessário utilizar uma malha que se adapte ao contorno deste corpo, o que pode causar o aumento do esforço computacional. Uma alternativa para diminuir o esforço computacional é a utilização do método das Fronteiras Imersas que possibilita a utilização de uma malha cartesiana nas simulações computacionais do escoamento em torno de obstáculos. Isso é feito adicionando um termo forçante nas equações que modelam o escoamento. Assim, a força que o fluido exerce sobre o contorno do obstáculo é transferida diretamente para a malha, que pode então ser cartesiana.

O objetivo deste trabalho de mestrado foi implementar, verificar e validar um código computacional baseado no Método das Fronteiras Imersas que possibilitasse a simulação do escoamento em torno de um cilindro circular. Foram simulados computacionalmente o escoamento em torno do cilindro em repouso, em torno do cilindro oscilando na mesma direção do escoamento, na direção perpendicular ao escoamento e para o caso em que o cilindro encontra-se rotacionando alternadamente em torno no próprio eixo. As simulações feitas utilizando este código possibilitaram a captura e a análise numérica do fenômeno de Atrelagem Síncrona, caracterizado pela sincronia entre a frequência de oscilação do cilindro e a frequência de desprendimento natural de vórtices deste mesmo cilindro.

A verificação e validação de código foram efetuadas utilizando diversos trabalhos numéricos e experimentais encontrados na literatura. Foram efetuadas comparações quan- 
titativas dos coeficientes de arrasto $C_{l}$ e sustentação $C_{d}$ e comparações qualitativas do desprendimento de vórtices e formato da esteira. Nos quatro tipos de escoamento simulados, o método proposto apresentou um bom desempenho, mostrando-se apto para simular estes tipos de escoamentos.

\subsection{Trabalhos Futuros}

Com a conclusão do presente trabalho, alguns direcionamentos para trabalhos futuros foram identificados. Dentre eles, efetuar um estudo mais completo dos resultados, utilizando Série de Fourier para comparar com maior exatidão analítica as frequências existentes no sinal dos coeficientes de arrasto e sustentação analisados durante este trabalho.

Uma forma de dar continuidade ao estudo do Método das Fronteiras Imersas seria a modelagem da turbulência, o que possibilitaria simular escoamentos para altos números de Reynolds. Além disso, poderia ser feita uma extensão do código proposto para o caso tridimensional.

Uma outra idéia seria a implementação do acoplamento de um sistema molaamortecedor ao cilindro. Isso possibilitaria simular a movimentação livre do cilindro, de acordo com as constantes adotadas. 


\section{Anexo A}

Este anexo apresenta os títulos dos artigos publicados e submetidos durante o desenvolvimento deste trabalho:

\section{Artigos publicados e aceitos:}

Artigo 1: Góis, E. R. C., Souza, L. F. Estudo Numérico do escoamento em tono de um cilindro oscilante utilizando a técnica das Froenteiras Imersas In: XXVIV CNMAC Congresso Nacional de Matemática Aplicada e Computacional, 2006, Campinas - SP.

Artigo 2: Góis, E. R. C., Souza, L. F.. Numerical study of lock-in phenomena in 2D flow over a cylinder, In: XII DINAME - International Symposium on Dynamics Problems, 2007, Ilhabela - SP.

Artigo 3: Dorício, J. L., Marques, A. C. H., Greco, P. C. Jr., Góis, E. R. C., Souza, L. F. "Simulação numérica de fluido incompressível ao redor de um cilindro com oscilação angular: Método da Fronteira Imersa e Método da Fronteira Virtual - In: XXX CNMAC - Congresso Nacional de Matemática Aplicada e Computacional, 2007, Florianópolis - SC.

Artigo 4: Góis, E. R. C., Souza, L. F. Numerical study of flow over a vibrating circular cylinder using a Immersed Boundary Method In: Fifth Conference on Bluff Body Wakes and Vortex-Induced Vibrations, 2007, Costa do Sauípe - BA.

Artigo 5: Góis, E. R. C., Souza, L. F. Numerical study of flow over a vibrating circular cylinder using a Immersed Boundary Method In: XIX Congresso Brasileiro de Engenharia Mecânica , 2007, Brasília - DF. 


\section{Referências Bibliográficas}

ARMSTRONG, B. J.; BARNES, F. H.; GRANT, I. The effect of perturbation on the flow over a cylinder. Physics of Fluids, v. 29, p. 2095 - 2192, 1986.

BAEK, S. J.; SUNG, H. J. Numerical simulation of the flow behind a rotary oscillating circular cylinder. Physics of Fluids, v. 10, n. 4, p. 869-876, 1998.

BARBI, C.; FAVIER, D. P.; MARESCA, C. A. Vortex shedding and lock-on of a circular cylinder in oscillatory flow. Journal of Fluid Mechanics, v. 170, p. 527-544, 1986.

BERGER, E.; WILLIE, R. Periodic flow phenomena. Ann. Rev. Fluid Mech, v. 4, p. 313-340, 1972.

BISHOP, R. E. D.; HASSAN, A. Y. The lift and drag forces on a circular cylinder in a flowing fluid. Proc. Ray. Soc. London Ser., v. 277, p. 32-50,, 1964.

BLACKBURN, H. M.; HENDERSON, R. D. A study of two-dimensional flow past an oscillating cylinder. Journal of Fluids Mechanics, v. 385, p. 255-286, 1999.

BRANDT, A. Multi-level adaptive solutions to boundary value problems. Mathematics of Computation, v. 31(138), p. 333 - 390, 1977.

CHOI, J. et al. An immersed boundary method for complex incompressible flows. Journal of Computational Physics, v. 224, p. 757-784, 2007.

CHOPRA, K. P.; HUBERT, L. F. Mesoscale eddies in wake of islands. J. Atmos. Science, v. 22, p. $652-657,1965$.

CUNFF, C. L. et al. Vortex-induced vibrations of risers: Theorical, numerical and experimental investigation. Ann. Rev. Fluid Mech., v. 57, p. 59-69, 2002.

FORTUNA, A. O. Técnicas Computacionais para Dinâmica dos Fluidos. [S.l.]: Edusp, 2000 . 
GRIFFIN, O. M. Flow similitude and vortex lock-on in bluff body near-wakes. Physics Fluids, v. 1, p. 697-703, 1988.

GRIFFIN, O. M.; RAMBERG, S. E. Vortex shedding from a cylinder vibrating in-line with an incident uniform flow. Journal of Fluid Mechanics, v. 75, p. 257 - 271, 1976.

GU, W.; CHYU, C.; ROCKWELL, D. Timing of vortex formation from a oscillating cylinder. Physics of Fluids, v. 6, p. 3677-3682, 1994.

LAI, M. C.; PESKIN, C. S. An immersed boundary method with formal second-order accuracy and reduced numerical viscosity. Journal of Computational Physics, v. 160, p. 705-719, 2000.

LAMBERT, J. D. Computational Methods in Ordinary Differential Equations. [S.1.]: John Wiley and Sons, 1973.

LIU, C.; ZHENG, X.; SUNG, C. H. Preconditioned multigrid methods for unsteady incompressible flows. Journal of Computational Physics, v. 139, p. 35-57, 1998.

LU, X. Y.; DALTON, C. Calculation of the timing of vortex formation from a oscillating cylinder. Journal of Fluids and Structures, v. 10, p. 527-541, 1996.

M.AL-MDALLAL, Q.; LAWRENCE, K. P.; KOCABIYIK, S. Forced streamwise oscillations of circular cylinder: Locked-on modes and resulting fluid forces. Journal of Fluids and Structures, v. 23, p. 681-701, 2007.

MEULEN, R. V. The immersed boundary methods for (2D) incompressible Navier-Stokes equations. Tese (Doutorado) — Delft University of Technology, 2006.

NOBARI, M. R. H.; NADERAN, H. A numerical study of flow past a cylinder with cross-flow and inline oscillation. Journal of Computational Physics, v. 35, p. 393-415, 2006.

OERTL, J. H. Wakes behind blunt bodies. Ann. Rev. Fluid Mech., v. 22, p. 539-564, 1990.

PESKIN, C. S. The immersed boundary method. Mathematics of Computation, v. 1, p. $479-517,2002$.

SOUZA, L. F. de. Instabilidade centrífuga e transição para turbulência em escoamentos laminares sobre superfícies côncavas. Tese (Doutorado) - Instituto Técnológico de Aeronáutica, ITA, 2003.

SOUZA, L. F. de. Numerical simulation of a flow over a circular cylinder usin a immersed boundary method in vorticity-velocity formulation. In: $18^{\circ}$ Congresso Internacional de Engenharia Mecânica. Ouro Preto/MG, Brasil: ABCM, 2005. 
